\title{
FINAL REPORT DE-FG02-07ER15894
}

\section{Part I. Abstract}

Project Title: Theory Aided Design of Active and Durable Nanoscale Cathode Catalysts

DOE Grant Number: DE-FG02-07ER15894

Principal Investigator: Matthew Neurock, Departments of Chemical Engineering and Chemistry, University of Virginia, Charlottesville, VA 22904-4741, Phone: (434) 924-6248. Fax (434) 982-2658. e-mail: mn4n@,virginia.edu

Postdoctoral Researcher: Michael Paul, Department of Chemical Engineering, University of Virginia, Charlottesville, VA 22904-4741, Phone: (434) 924-7778. Fax (434) 982-2658. e-mail: mp5ke@virginia.edu

Graduate Student: Anirban Chatterjee, Department of Chemical Engineering, University of Virginia, Charlottesville, VA 22904-4741, Phone: (434) 924-7778. Fax (434) 982-2658. e-mail: ac4wd@,virginia.edu, and David Hibbitts, Department of Chemical Engineering, University of Virginia, Charlottesville, VA 22904-4741, Phone: (434) 924-7778. Fax (434) 982-2658. e-mail: ddh9r@virginia.edu, Fei Li, Department of Chemical Engineering, University of Virginia, Charlottesville, VA 22904-4741, Phone: (434) 924-7778. Fax (434) 982-2658. e-mail: fl3p@,virginia.edu

Yearly Budget: $\$ 135,000$

Period of Execution: 09/01/09-June 1, 2012

\section{Overall Goals and Objectives and Achievements}

One of the greatest technological hurdles to deployment of fuel cells relates to the sluggish activity, low durability and the high cost of the catalysts that are currently employed. For automotive PEM fuel cells to become commercially viable, the Pt-specific power density would need to be reduced to less than $0.2 \mathrm{gPt} / \mathrm{kW}$ (at cell voltages $>0.65 \mathrm{~V}$ ). This would require the Pt loadings to be less than $0.15 \mathrm{mg}_{\mathrm{Pt}} / \mathrm{cm}^{2}{ }_{\text {MEA }}$ within the membrane electrode assembly. [4] This could be achieved by enhancing the catalytic activity at the cathode, thus lowering its overpotential. Various different Pt-alloys have shown 2-4 times enhanced activities over Pt alone but still suffer some of the same durability issues as that of the pure Pt. [5-16] There is a general loss of active Pt due to dissolution and sintering. While there have been a number of elegant fundamental experimental [5-16] and theoretical [5-16] studies on ideal single crystal Pt and Pt alloy surfaces which have helped to elucidate the factors that control the activity, there have been very few fundamental studies focused on the stability, reactivity and durability of well-defined Pt nanoparticles. We carried out ab initio density functional theory together with a novel double reference method that we developed to simulate constant potential electrochemical systems in order to model the electrocatalytic reduction of oxygen over model Pt alloy surfaces and nanoparticles. These simulations were used to probe the factors that control the electrocatalytic activity, guide the potential selection of new materials and test their stability under reaction conditions. Ab initio calculations were used to determine the reaction energies 
and activation barriers for a comprehensive array of different elementary adsorption, desorption, surface reaction and diffusion steps over Pt and Pt alloys involved in the electroreduction of oxygen as a function of surface coverage, the electrochemical potential and temperature. The calculations were used to simulate the potential dependent adsorption and surface reaction energies along with activation barriers in order to determine the kinetics for different surface structures and structural features (step edge and corner sites) to provide the necessary input for kinetic Monte Carlo simulations to follow the rates of reaction. More coarse-grained simulated annealing methods were used to help establish the lowest energy structures and morphologies for different Pt and Pt-alloy nanoparticles that form. The results from the DFT calculations were used to establish an ab initio-derived kinetic database that was used in both 2D and 3D kinetic Monte Carlo simulations that were used to follow the electrocatalytic performance over different particle sizes, shapes and compositions. The ab initio calculations together with the kinetic Monte Carlo simulations were used to complete the following objectives: 1) Determine the controlling elementary reaction pathways and intrinsic kinetics involved in ORR and their potential dependent behavior; 2) Establish the influence of the extrinsic reaction environment including surface structure, alloy composition and spatial arrangement and the humidity on ORR kinetics; 3) Elucidate the effects of particle size and morphology as well as the atomic structure and composition of nanoparticles of $\mathrm{Pt}, \mathrm{Pt}_{3} \mathrm{Co}, \mathrm{Pt}_{3} \mathrm{Ni}, \mathrm{Pt}_{3} \mathrm{Fe}$ and other Pt-alloys on the electrocatalytic activity and reaction selectivity; 5) Construct surface Pourbaix phase diagrams for different Pt and Pt-alloys in order to map out the most stable surface phases for different material compositions and reaction conditions; 6) Elucidate the mechanisms that control dissolution and re-deposition of Pt.

\section{Potential Impact on DOE}

The goals of the proposed research were to elucidate and control electrocatalysis at the aqueous/metal interface for PEM fuel cell systems. This matches the longer term DOE Basic Energy Science program measure of understanding, modeling, and controlling of chemical reactions on surfaces for energy-related applications, employing lessons from inorganic, organic and self-assembling systems. The methods developed along with the knowledge gained should crosscut various areas in electrocatalysis, catalysis and electrochemistry important to BES. The proposed effort will utilize the tools developed herein to aid in the design novel alloy catalysts for the cathode that are active and resilient to dissolution and degradation. This is directly related to the long term BES program measure of "designing, modeling, fabricating, characterizing, analyzing, assembling and using new materials and structures, including metals and alloys, particularly at the nanoscale, for energy-related applications.”

\section{Part II. Description of the Results:}

\section{First Principles Simulation of the Elementary Steps in Oxygen Reduction Reaction over Pt Under Electrocatalytically Relevant Conditions.}

In order to establish the appropriate elementary steps and kinetics for the oxygen reduction reaction under working electrocatalytic conditions we explicitly modeled the aqueous metal interface and followed the potential dependent behavior using ab initio density functional theoretical calculations along with the double reference method developed by Filhol and Neurock $[17,18]$. These are the first simulations that take into account the detailed potential 
dependence and aqueous metal interface directly. The mechanism which is shown in Fig. 1 proceeds via the adsorption of molecular oxygen onto the Pt surface.

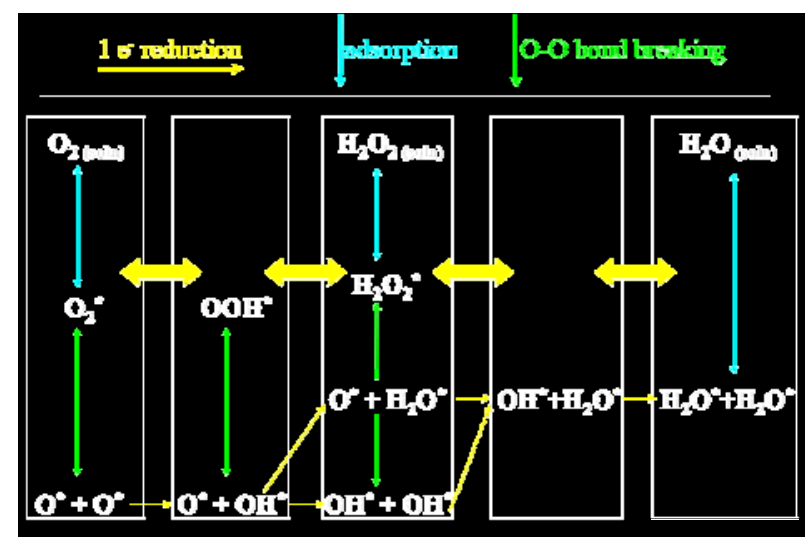

Figure 1. Reaction pathways for the reduction of oxygen over Pt. [3]

Oxygen can either dissociate or react via a proton-coupled electron transfer step to form the surface peroxo intermediate. The results depicted in Fig. 2 show that the barrier to dissociate $\mathrm{O}_{2}$ at moderate coverages of water is over $0.8 \mathrm{eV}$ for a wide range of potentials. The barrier does not change with potential as this is not an electrocatalytic step. The barrier is $1.5 \mathrm{eV}$ at more realistic coverages of 0.5 monolayers of $\mathrm{OH}$ on the surface. These results indicate that the direct dissociation of oxygen does not occur at any of the potentials examined. [3]

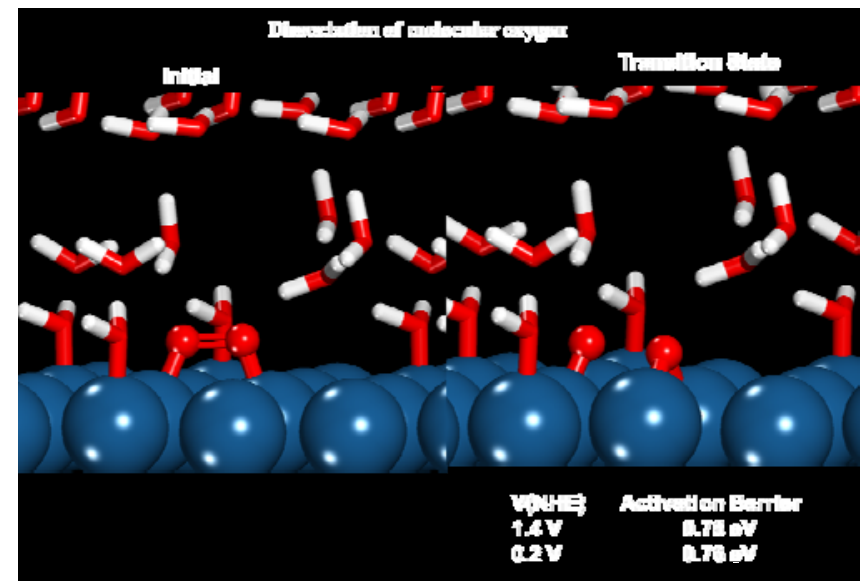

Figure 2. Potential dependent dissociation of molecular $\mathrm{O}_{2}$ over $\mathrm{Pt}(111)$. [3]

Molecular oxygen instead reacts via a proton-coupled-electron transfer process to form a surface peroxo intermediate as is shown in Fig. 3. At the ideal reversible potential of $1.2 \mathrm{~V}$, the barrier to transfer the proton from the solution phase to the $\mathrm{O}_{2}$ bound at the positively charged $\mathrm{Pt}$ surface requires overcoming an activation energy of $0.75 \mathrm{eV}$ which is prohibitive. 


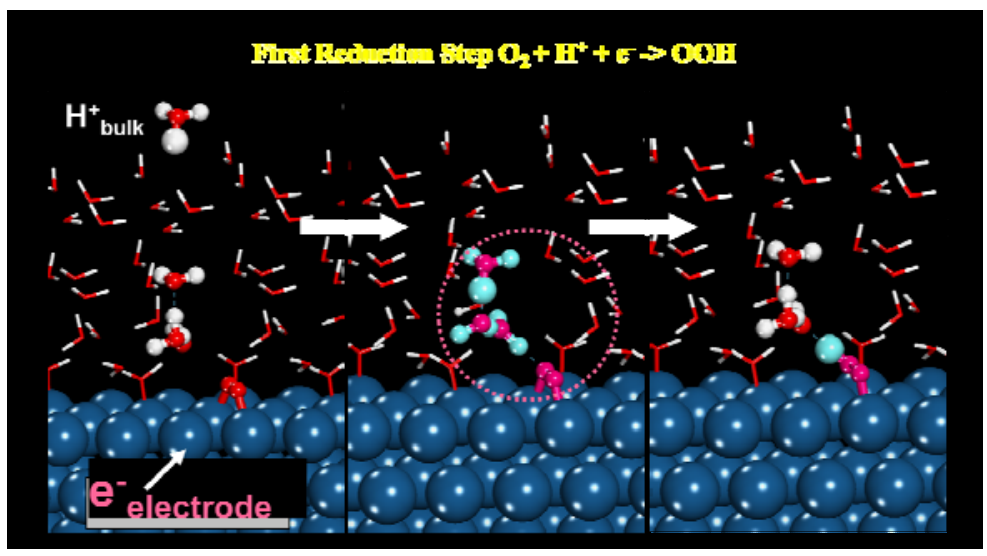

Figure 3. DFT-calculated potential dependent reduction of $\mathrm{O}_{2}$ to $\mathrm{OOH}$ over $\mathrm{Pt}(111)$. [3]

The activation barrier, however, was found to exponentially depend upon the potential. The barrier is reduced from $0.75 \mathrm{eV}$ at $1.2 \mathrm{~V}$ to $0.3 \mathrm{eV}$ at $0.8 \mathrm{~V}$. The calculated activation barrier closely follows the surface reaction energy over a range of potentials as shown in Fig. 4. The results are fully consistent with experimental results from the literature over this same range which is shown in Fig. 5.

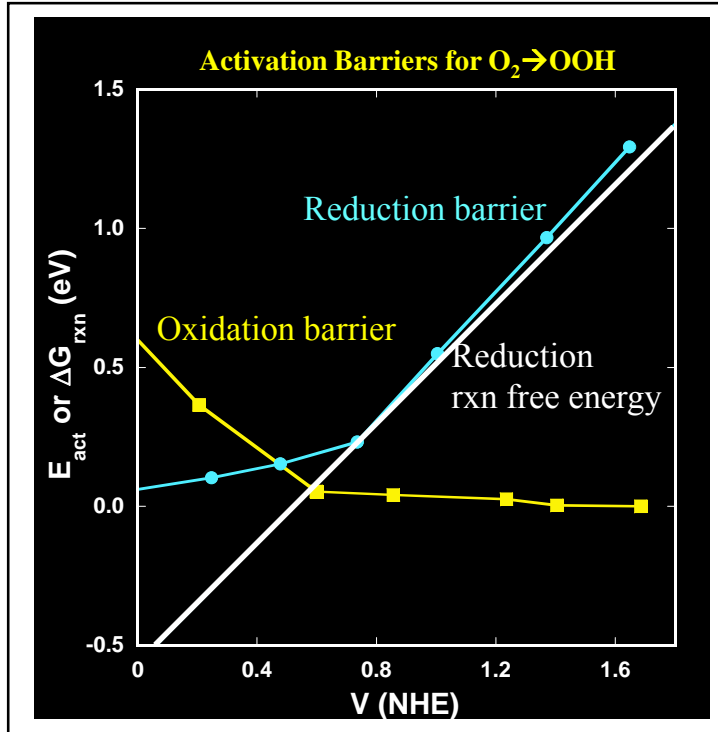

Figure 4. DFT-calculated potential dependent reductionbarriers and reaction energies for $\mathrm{O} 2$ to $\mathrm{OOH}$ and oxidation barriers for $\mathrm{OOH}$ to $\mathrm{O} 2$ [3]

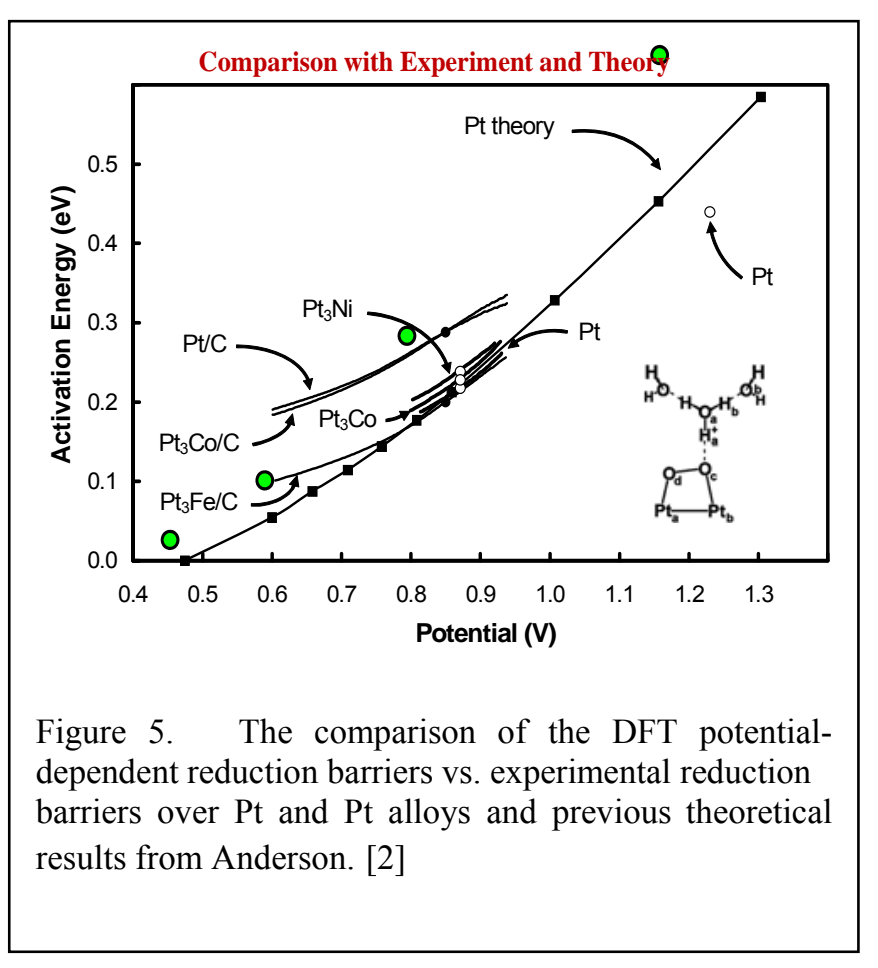


The peroxo intermediate that forms at potentials less than $1 \mathrm{~V}$ can readily dissociate over a range of electrochemical potentials to form adsorbed oxygen $\left(\mathrm{O}^{*}\right)$ and hydroxide $\left(\mathrm{OH}^{*}\right)$ on the $\mathrm{Pt}$ surface. The barrier for this reaction is rather low $(0.06$ at $1.2 \mathrm{~V}$ to $0.41 \mathrm{eV}$ at $0.2 \mathrm{~V})$ as is shown in Fig. 6 and does not change very much with potential as this reaction does not directly involve protons or electrons.

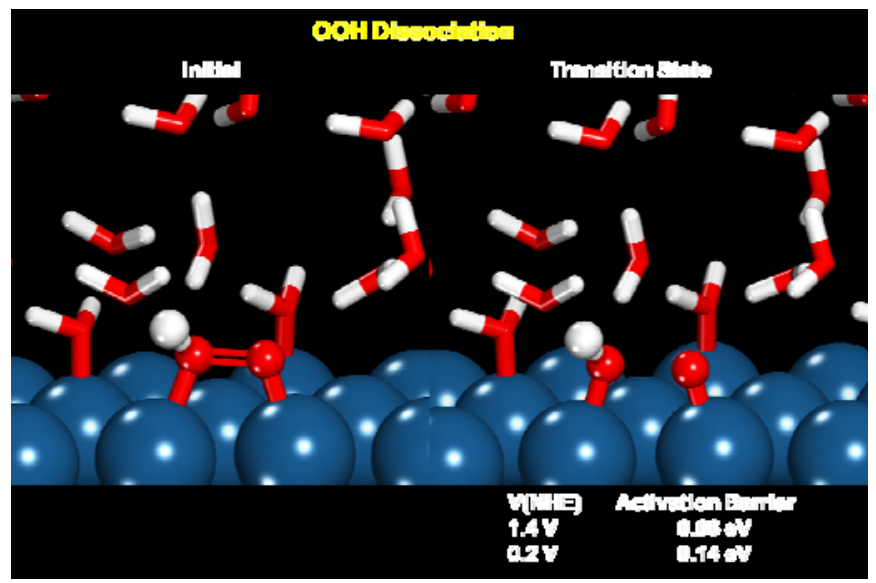

Figure 6. DFT-calculated potential-dependent dissociation of $\mathrm{OOH}^{*}$ to $\mathrm{O}^{*}$ and $\mathrm{OH}^{*}$ over $\mathrm{Pt}(111)$.

The potential dependent reaction energies and activation barriers were used to construct constant potential energy diagrams the follow the reaction at a given constant potential. Figure 7 shows the overall reaction energies if the cell is operated at the optimal cell efficiency of $1.2 \mathrm{~V}$. At this high of potential, the barrier to activate molecular oxygen is over 0.7 which will not occur. The barrier for the proton coupled electron transfer to an adsorbed molecular oxygen also requires 0.7 $\mathrm{eV}$ to form the surface peroxo $\left(\mathrm{OOH}^{*}\right)$ intermediate which can readily dissociate with a barrier of only $0.2 \mathrm{eV}$ to form $\mathrm{O}^{*}$ and $\mathrm{OH}^{*}$ intermediates. This reaction is exothermic at $0.82 \mathrm{eV}$. The subsequent reduction of $\mathrm{O}^{*}$ and $\mathrm{OH}^{*}$ intermediates on $\mathrm{Pt}$ were found to be prohibitive at $1.2 \mathrm{~V}$ over $1.6 \mathrm{eV}$ in terms of energy to form water from $\mathrm{OH}^{*}$. The results indicate that the reaction will not proceed at these high potentials. This is consistent with experimental results which show no current densities above about $1 \mathrm{~V}$.

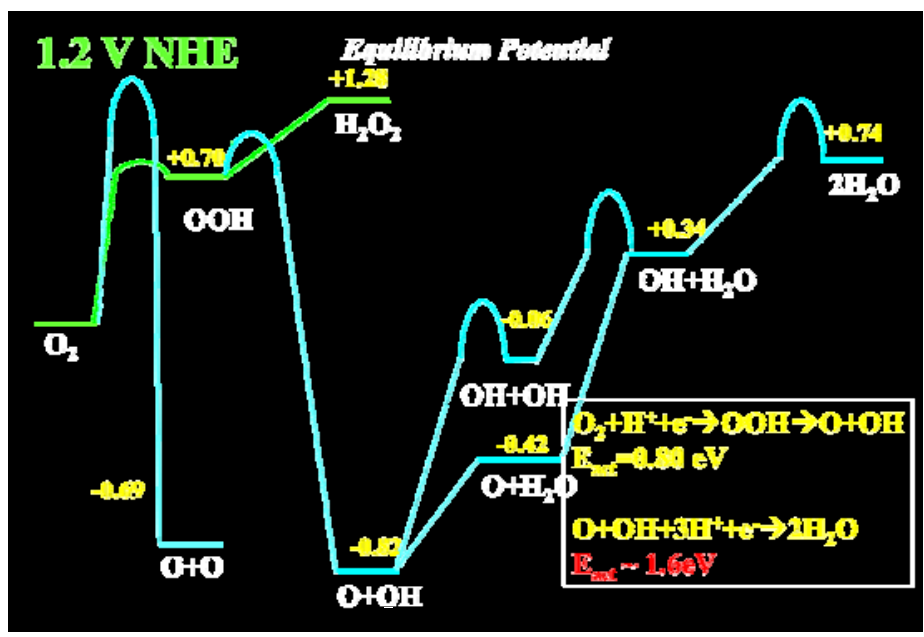

Figure 7 Full DFT-calculated potential energy surface for the reduction of oxygen over 
If the potential is lowered to $0.8 \mathrm{~V}$, there is a significant change in the overall potential energy diagram as is shown in Fig. 8 . At $0.8 \mathrm{~V}$, the barrier to activate $\mathrm{O}_{2}$ to form the surface peroxo intermediate is now only $0.34 \mathrm{eV}$.

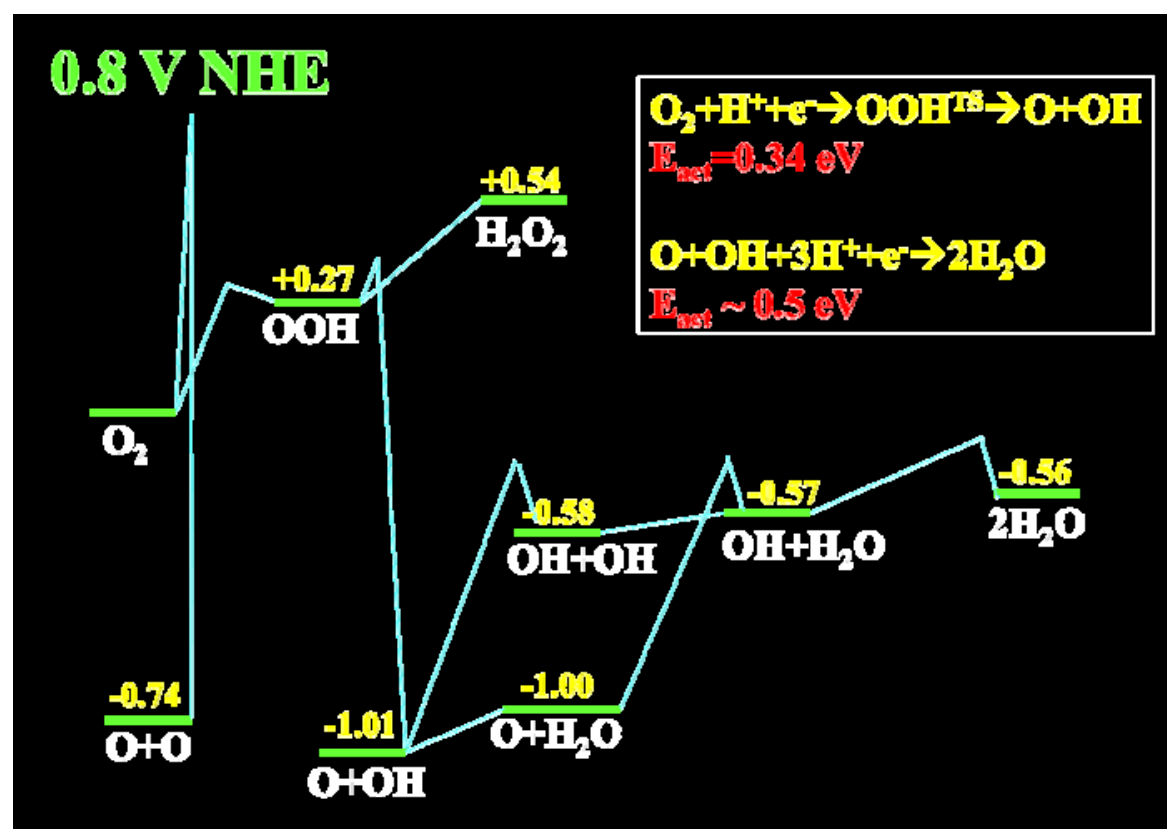

Figure 8 Full DFT-calculated potential energy surface for the reduction of oxygen over $\mathrm{Pt}(111)$ at $0.8 \mathrm{~V}$.

The lower potential makes it much easier to drive the proton from solution to the Pt surface as it is no longer so positively charged. The barrier for this initial PCET reaction at $0.8 \mathrm{~V}$ is consistent with the experimental results depicted in Fig. 5 which show an activation barrier of $0.26 \mathrm{eV}$ at $0.8 \mathrm{~V}$. The surface peroxo intermediate readily dissociates as was shown in Fig. 6 with an energy of only $0.06 \mathrm{eV}$. The subsequent reduction of the $\mathrm{O}^{*}$ and $\mathrm{OH}^{*}$ intermediates from $\mathrm{Pt}$ at $1.2 \mathrm{~V}$ requires an effective activation barrier of at least $1.6 \mathrm{eV}$ as is shown in Fig. 7. This kills the reaction and as such there is no current density measured above $1.0 \mathrm{~V}$ as reported in the literature $[11,13]$. If the potential is reduced even further to $0.7 \mathrm{~V}$. The limiting surface reaction becomes the initial reduction of $\mathrm{O}_{2}{ }^{*}$ to form the surface peroxo intermediate. This is consistent with experimental results which indicate that peroxo formation step limits the rate at lower potentials on Pt. The change in the rate controlling step that is found at $0.7 \mathrm{~V}$ is consistent with the experimental results which show two Tafel slopes at 0.77 Vwhich would suggest a change in the steps that control the mechanism. [19]

The results here provide the first detailed mechanistic analysis of the reaction energies and barriers for the range of steps involved in the reduction of oxygen as a function of potentials. 


\section{The Role of Alloying Pt with a Second Metal.}

The results on $\mathrm{Pt}$ indicate that the reduction of $\mathrm{O}^{*}$ and $\mathrm{OH}^{*}$ control the rate at potentials greater than $0.8 \mathrm{~V}$ whereas $\mathrm{O}_{2}$ reduction controls the rate below $0.8 \mathrm{~V}$. The crossover between these two steps is controlled by the metal-oxygen bond strength. As has been demonstrated previously [6$8,20-23]$, the tolerance of the cathode to $\mathrm{OH}^{*}$ poisoning can by moderated by alloying Pt. Herein we used the detailed potential-dependent simulations for the $\mathrm{O}^{*}+\mathrm{OH}^{*}$ and $\mathrm{O}_{2}$ reduction steps that control the rate to show that these steps are inversely related to the metal-oxygen bond strength. Strong $\mathrm{M}-\mathrm{O}$ bonds significantly favor $\mathrm{O}_{2}$ reduction as $\mathrm{O}_{2}$ binds to the surface quite strongly which aids in the activation of the O-O bond. Stronger $\mathrm{M}-\mathrm{O}$ bonds, however, inhibit the rate and increase the barriers for the $\mathrm{OH}^{*}$ and $\mathrm{O} *$ reduction. The $\mathrm{OH}^{*}$ and $\mathrm{O}_{2} *$ reduction barriers for pseudomorphic overalayers of $\mathrm{Pt}$ on $\mathrm{Au}, \mathrm{Pd}, \mathrm{Pt}$ and $\mathrm{Ru}$ which are depicted in Fig. 9 show that the optimal $\mathrm{M}-\mathrm{O}$ bond strength at $0.8 \mathrm{~V}$ would occur at $-3.87 \mathrm{eV}$. Both $\mathrm{Pt}$ and $\mathrm{Pt} / \mathrm{Pd}$ lie very close to the optimal M-O bond strength which would help to explain why these metals are optimal at lower potentials. [24]

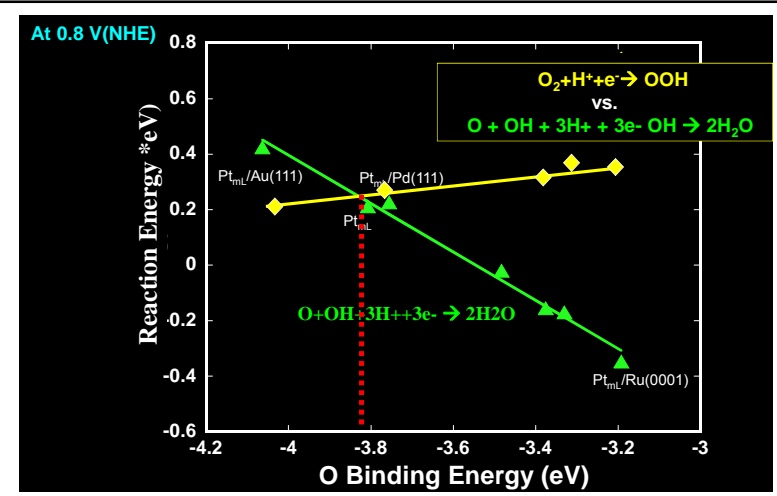

Figure 9. DFT-calculated reaction energies for $\mathrm{O}_{2} *$ reduction (yellow) and $\mathrm{O}^{*}$ and $\mathrm{OH}^{*}$ reduction (green) vs. $\mathrm{O}^{*}$ binding energies for a range of different Pt alloys (pseudomorphic over layers of Pt on different metals) at $0.8 \mathrm{~V}$. The cross-over point determines the optimal $\mathrm{O}^{*}$ that balances the reduction of $\mathrm{O}_{2} *$ and $\mathrm{OH}^{*}+\mathrm{O}^{*}$.

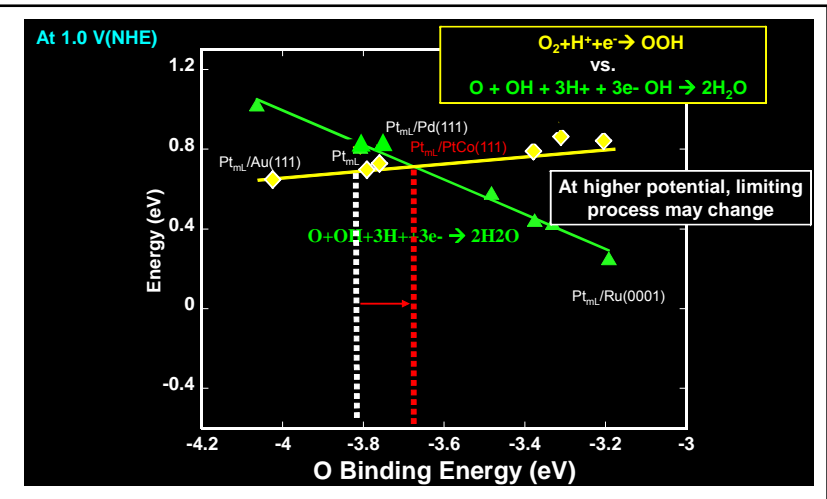

Figure 10. DFT-calculated reaction energies for $\mathrm{O}_{2} *$ reduction (yellow) and $\mathrm{O}^{*}$ and $\mathrm{OH}^{*}$ reduction (green) vs. $\mathrm{O}^{*}$ binding energies for a range of different $\mathrm{Pt}$ alloys (pseudomorphic over layers of $\mathrm{Pt}$ on different metals) at $1.0 \mathrm{~V}$. The cross-over point determines the optimal $\mathrm{O}^{*}$ that balances the reduction of $\mathrm{O}_{2} *$ and $\mathrm{OH}^{*}$ $+\mathrm{O}^{*}$.

As we increase the operating potential to the thermodynamic limit of $1.2 \mathrm{~V}$, both the $\mathrm{O}_{2}$ and $\mathrm{O}+$ $\mathrm{OH}$ reduction curves shift upwards thus resulting in higher activation barriers. The shift in the reduction of $\mathrm{O}+\mathrm{OH}$ is much more dramatic as we increase the potential. As a result, the point at which these two lines cross shifts to the right thus requiring weaker M-O bond strength ( -3.65 $\mathrm{eV}$ ) in order to avoid poising of the surface by $\mathrm{O}^{*}$ or $\mathrm{OH}^{*}$ intermediates. The optimal pseudomorphic overlayer alloy structure would be $\mathrm{Pt} / \mathrm{Co}$ which is consistent with the experimental results which indicate that the PtCo demonstrate significantly improved overpotentials for oxygen reduction. In order to examine the PtCo systems further we examined the stability of different PtCo alloy structures to dissolution in water over a range of potentials and compare them with that over Pt alone. 


\section{Potential Dependent Activation of Water and the Dissolution of Metals over Pt and PtCo Alloys}

\section{A. Activation of Water over $\mathrm{Pt}_{21} \mathrm{Co}_{6}$ Alloy/Water Interfaces}

We have used the double reference method to examine the electrochemical activation of water over two different $\mathrm{Pt}_{21} \mathrm{Co}_{6}$ (111) alloy surfaces in the presence of an aqueous medium. The first examines a welldefined segregated surface alloy where Co atoms are uniformly placed throughout the surface (see Fig. 11A). The second structure involves a pseudomorphic $\mathrm{Pt} / \mathrm{Co} / \mathrm{Pt}(111)$ interface where an overlayer of $\mathrm{Pt}$ is placed upon Co which is bound to a $\mathrm{Pt}(111)$ substrate as is shown in Fig. 11B.

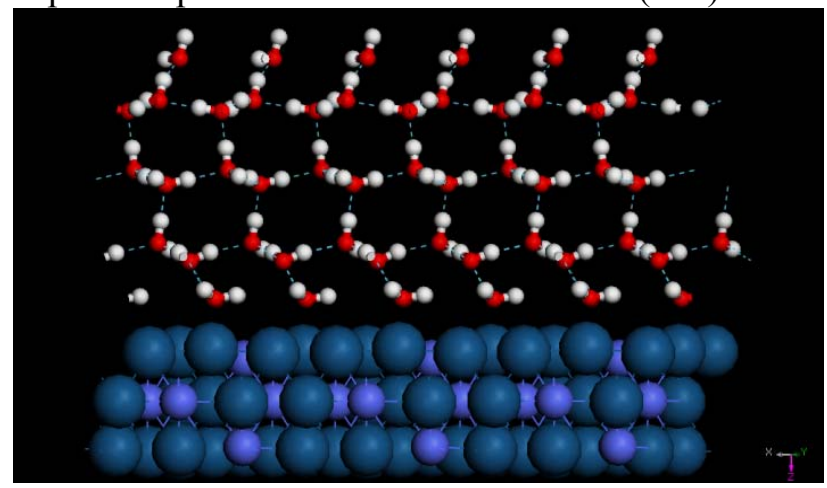

(a)

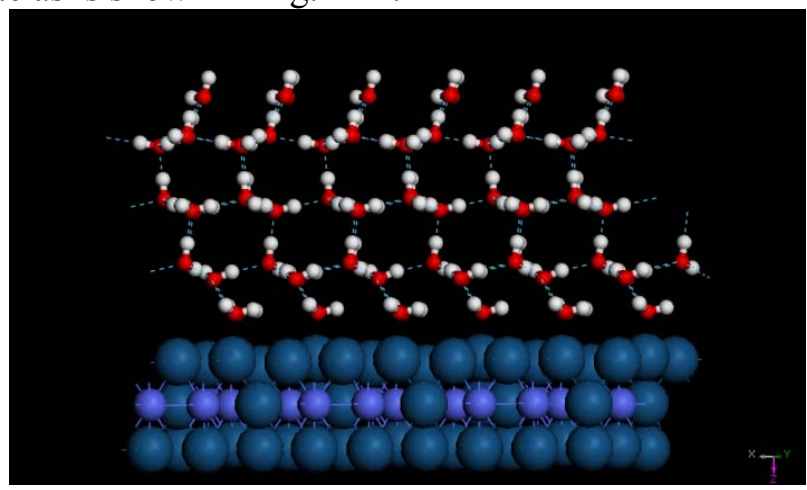

(b)

Fig. 11 - Water structure over the $\mathrm{Pt}_{21} \mathrm{Co}_{6}$ (111) alloy surface with Co atoms (a) in the top layer of the slab and (b) concentrated in the center of the slab to give an overlayer of $\mathrm{Pt}$ atoms.

The activation of water was considered on the surface Co and Pt atoms on the alloy surface. The double reference method was used to follow the lowest energy structures and to examine the potentials which result in the activation of water as well as the dissolution of both $\mathrm{Pt}$ and Co from the surface. The simulations were also used to establish the potential at which $\mathrm{H}_{2} \mathrm{O}, \mathrm{OH}, \mathrm{O}$ and $\mathrm{H}$ become the energetically favored surface intermediates. The calculated structures for the different surface intermediates in the presence of solution are shown in Fig. 12. These structures are very similar to those found on the other alloy surface.

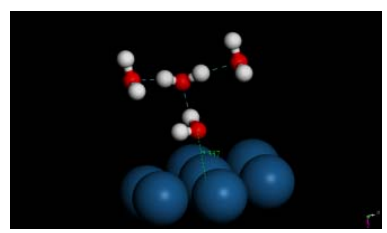

(a)

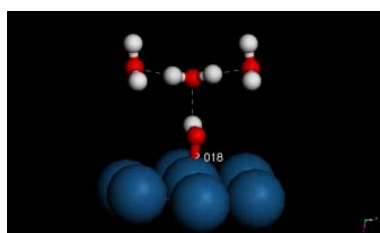

(b)

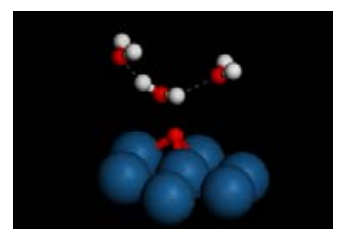

(c)

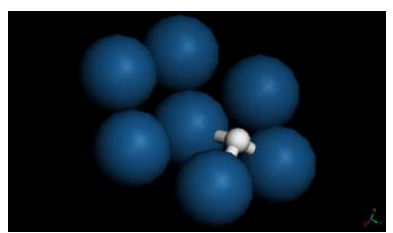

(d)

Fig. 12 - Local energy adsorption modes for (a) $\mathrm{H}_{2} \mathrm{O}$, (b) $\mathrm{OH}$, (c) $\mathrm{O}$ and (d) $\mathrm{H}$ species on the Pt overlayer surface.

Water tends to form a hexagonal bilayer structure on both of these alloy surfaces where the water molecules closest to the surface orient in such a way to place the $\mathrm{O}$ atom in an atop position at $2.33 \AA$ above the Pt atom. The water molecule forms hydrogen bonds to neighboring water molecules in the water network at the interface. Water activates at higher potentials on Pt to form stable hydroxyl intermediates with Pt-O distance of $2.01 \AA \AA$. Hydroxyl intermediates subsequently dissociate to form atomic oxygen and hydrogen which preferentially bind to the hep sites.

Each of these unique reduction and oxidations states of water (hydride, water, hydroxide, oxide) on Pt are plotted as a function of potential as shown in Fig. 13. The results were established using the double reference method. The hydride phase is most stable up until $0.16 \mathrm{~V}$ vs. NHE whereby there is a phase change and water becomes the most stable surface. Further increases in the potential lead formation of the oxide at $0.5 \mathrm{~V}$ and the hydroxide at $0.63 \mathrm{~V}$ vs. NHE as is shown in Fig. 13 and Table 1. 


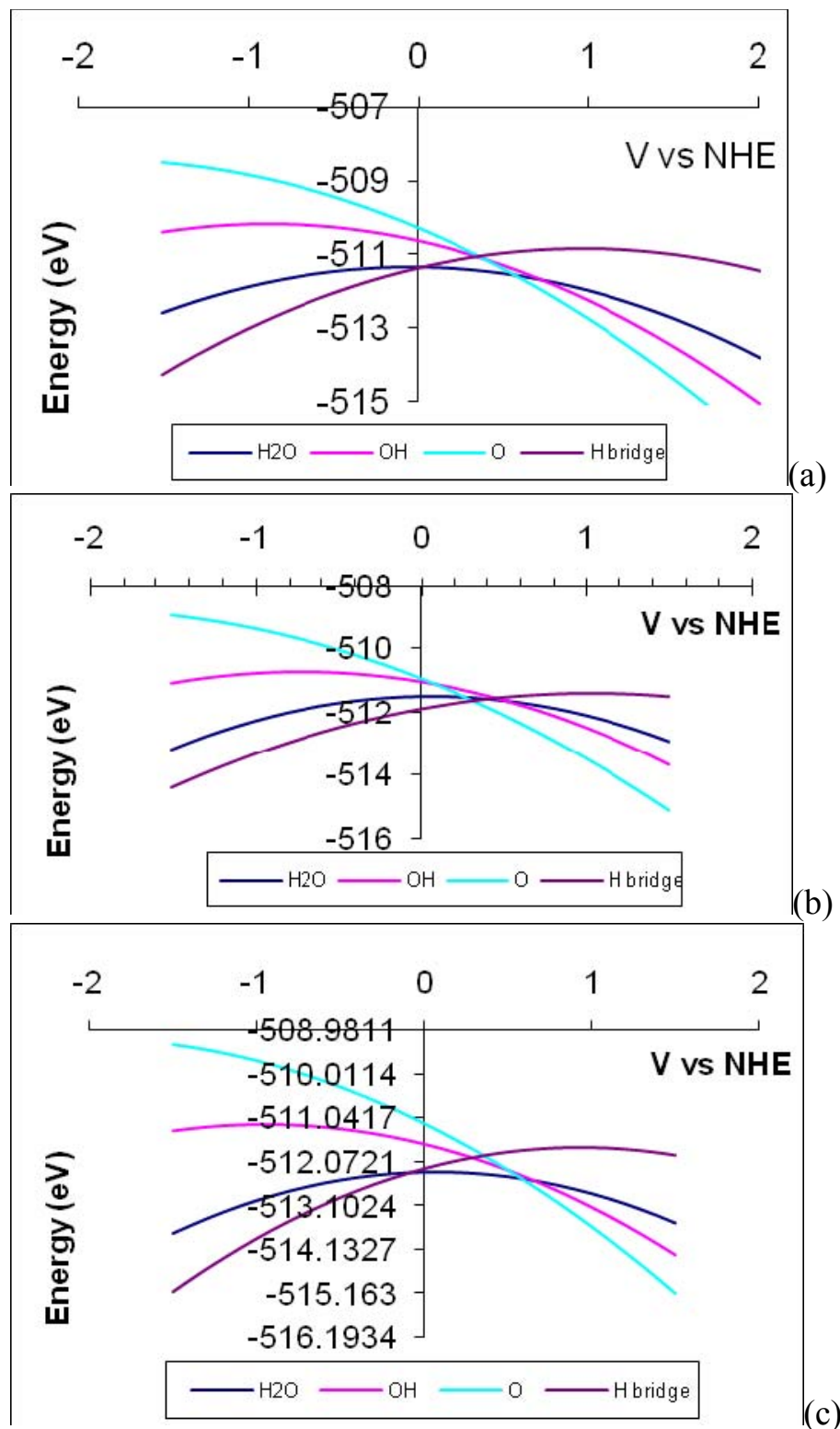

Fig. 13. - Potential versus energy plots for the $\mathrm{Pt}_{21} \mathrm{Co}_{6}(111)$ alloy surface/water interface with the species adsorbed to (a) a Pt atom on a mixed Pt/Co surface layer, (b) a Co atom on a mixed Pt/Co surface layer, (c) a Pt atom on a pure Pt surface overlayer. 
Table 1 - Comparison of the potentials at which the energies of the surfaces with the $\mathrm{H}, \mathrm{OH}$ and $\mathrm{O}$ adsorbates are equal to the energy of the surface with the $\mathrm{H}_{2} \mathrm{O}$ adsorbate.

\begin{tabular}{|l|l|l|l|}
\hline System & H/H2O (V) & H2O/O (V) & H2O/OH (V) \\
\hline Pt27(111) Surface & 0.16 & 0.50 & 0.63 \\
\hline $\begin{array}{l}\text { Pt21Co6 (111) Surface } \\
\text { with Absorption to Pt }\end{array}$ & 0.02 & 0.56 & 0.71 \\
\hline $\begin{array}{l}\text { Pt21Co6 (111) Surface } \\
\text { with Absorption to Co }\end{array}$ & 0.42 & 0.27 & 0.49 \\
\hline $\begin{array}{l}\text { Pt21Co6 (111) Surface } \\
\text { with Absorption to Pt } \\
\text { on a Pt overlayer }\end{array}$ & -0.09 & 0.58 & 0.60 \\
\hline
\end{tabular}

The results shown in Fig. 13a and b and summarized in Table 1 indicate that the addition of Co into Pt improves the performance of $\mathrm{Pt}$ which is consistent with the experimental and theoretical findings in the literature. [2-4, 7-10, 17-21] The current thought is that Co separates out and undergoes dissolution from the surface layer and is instead concentrated in the subsurface.

The results can be summarized as follows:

1. Water is much more readily activated on the surface Co atoms than on the Pt atoms. This can be readily seen in comparing Fig. 13(a) and (c), where the activation occurs over a Pt atom, with the results in Fig. 13(b) where the activation occurs over a Co atom. There is no range in potential on the alloy surface shown in Fig. 13b where adsorbed water is predicted to have the lowest energy on the Co surface atoms.

2. The adsorbed hydride phase is predicted to be the lowest energy state at potentials lower than $1 \mathrm{~V}$ vs. NHE whereas the adsorbed oxide phase is the lowest energy state at high potential for all three of the alloy surface examined.

3. The adsorbed hydroxide phase always appears to be a metastable intermediate

4. The addition of $\mathrm{Co}$ at the surface or within the subsurface increases the oxidation potential and decreases the reduction potential on Pt sites needed to activate water thus increasing its stability over a much wider range of potentials than on pure Pt alone as is seen in Table 1.

5. The largest predicted range for stable water adsorption is for the system with the $\mathrm{Pt}$ overlayer and all Co atoms in the subsurface layer. This is consistent with both experimental and theoretical studies which indicate that the presence of subsurface Co enhances the stability of water. 


\section{B. Dissolution of Co and Pt atoms from a $\mathrm{Pt}_{21} \mathrm{Co}_{6}$ alloy (111)/Water Interface}

The double reference method was also used to examine the potentials at which dissolution of Co and Pt ions from the $\mathrm{Pt}_{21} \mathrm{Co}_{6}$ (111) surface proceed at the alloy/solution interface. The dissolution of Co and $\mathrm{Pt}$ ions ultimately lead to the formation of a surface vacancy which was either left empty or occupied with an $\mathrm{O}$ atom or an $\mathrm{OH}$ species. The dissolution proceeds via the formation of an ionic $\mathrm{Pt}$ or Co complex with stabilizing four water molecule ligands adoption a square planar coordination complex in the first layer of solution as is seen in Fig. 14.

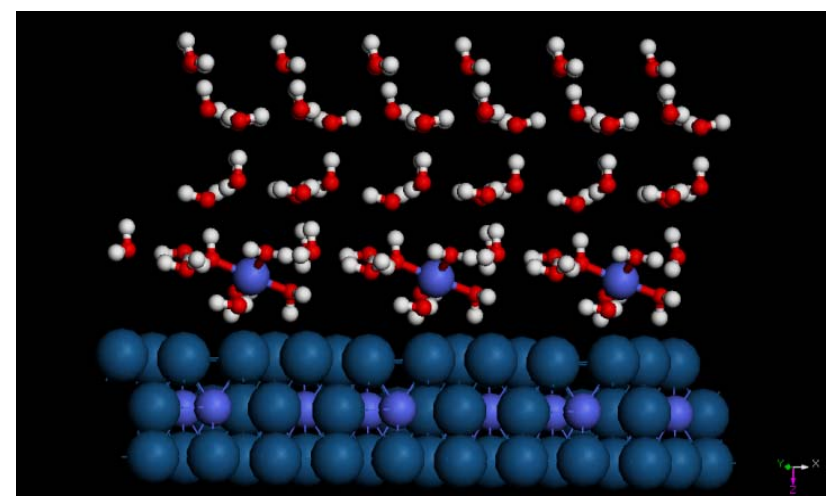

(a)

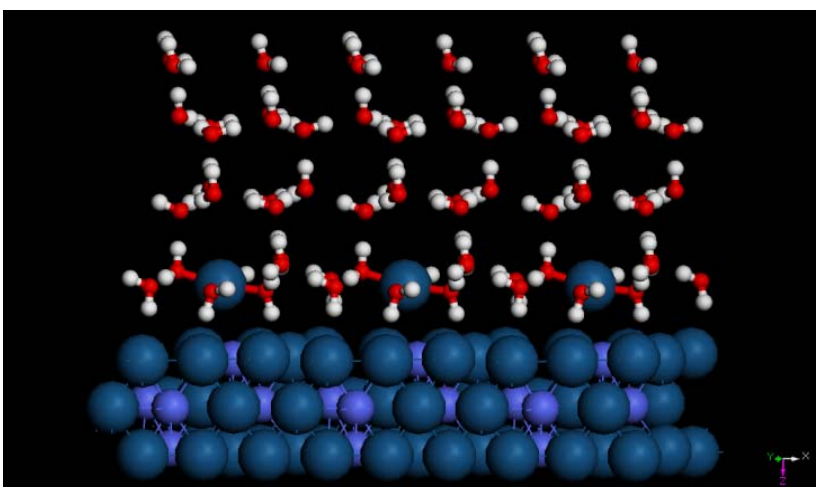

(b)

Fig. 14 - Conformations of the $\mathrm{Pt}_{21} \mathrm{Co}_{6}$ alloy (111)/water systems with one of the (a) Co and (b) Pt atoms placed into the water layer.

The potentials at which both Co and Pt ions can undergo dissolution and migrate into the water layer are shown in Fig. $15 \mathrm{a}$ and $\mathrm{b}$ respectively. The results from both of these plots indicate that metal ion dissolution requires the formation of a local oxide in order stabilize the resulting surface metal as the vacancy is readily capped by oxygen adatoms. As might be expected, the dissolution of either Pt or Co ions leaving a free vacancy within the metal surface is energetically unfavorable regardless of the potential. Dissolution thus tends to require the formation of either an $\mathrm{OH}$ or an $\mathrm{O}$ atom to bind to the ensuing vacancy in order to stabilize the overall reaction.

Table 2 compares the potentials at which the dissolved metal ion with the binding of an $\mathrm{O}$ in the resulting vacancy has the same energy as the unperturbed system and the same energy as the dissolved atom with an $\mathrm{OH}$ in the vacancy for both atom species. At both cross over energy points shown, the Co atom is shown to be more readily dissolved than the Pt atom.

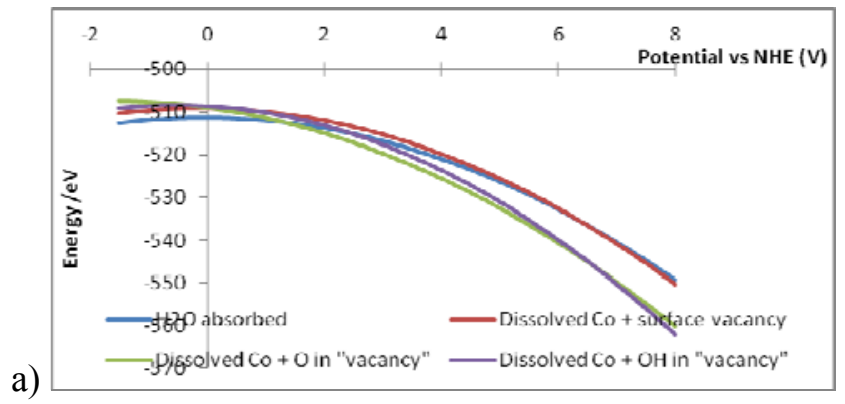

Fig. 15 - Potential versus energy plots for the investigation of the dissolution of surface (a) Co and (b) Pt atoms into the water layer. 
Table 2 - Comparison of the potentials at which the systems considerd have equal energies for the dissolution of Co and $\mathrm{Pt}$ atoms.

\begin{tabular}{|c|c|c|}
\hline Compared Systems & Co $(\mathrm{V})$ & $\mathrm{Pt}(\mathrm{V})$ \\
\hline $\begin{array}{c}\text { Adsorbed } \mathrm{H}_{2} \mathrm{O} / \text { Dissolved with O in } \\
\text { vacancy }\end{array}$ & 1.36 & 2.98 \\
\hline $\begin{array}{c}\text { Dissolved with O in } \\
\text { vacancy/Dissolved with OH in } \\
\text { vacancy }\end{array}$ & 6.67 & 7.08 \\
\hline
\end{tabular}

\section{Influence of Surface Structure}

The results above suggest that the dissolution of $\mathrm{Pt}$ and Co ions require higher potentials in order to pull the metal ions from coordinatively saturated sites on the surface. It is much more likely that the dissolution of metal atoms from coordinatively unsaturated surface sites present at edge and corner sites would be energetically much more favorable. We therefore examined a range of other metal surface structures including the: (100) and stepped (221) surfaces and large clusters containing $147 \mathrm{Pt}$ atoms surrounded by 428 water molecules. We have optimized the most favorable water conformations on these structures as seen in Fig. 16, and are currently examining their reactivity and their potential dependence. The results were used to help establish important structure properties relationships which govern dissolution.

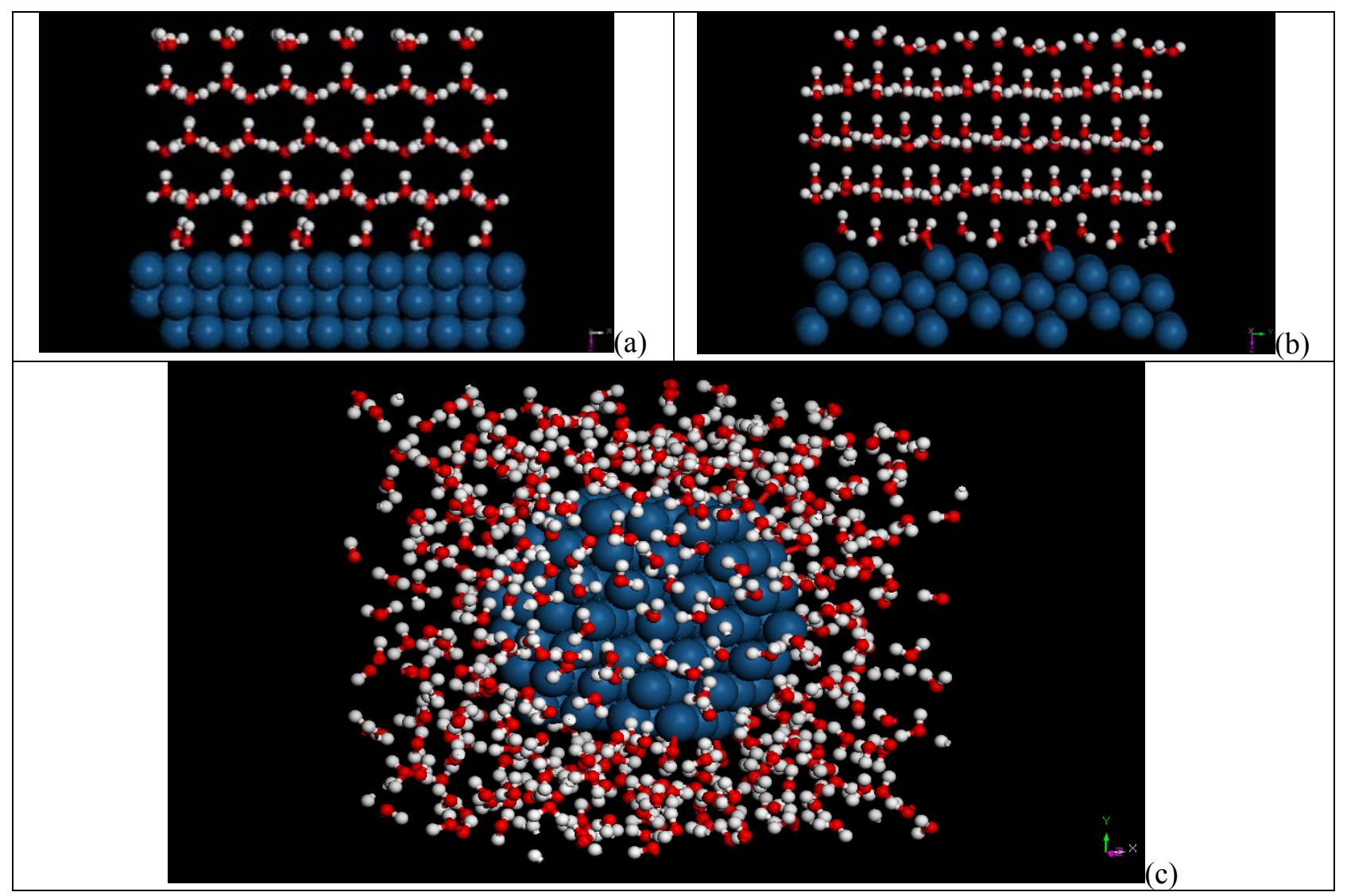


Fig. 16 - Conformations for the investigation of different Pt/Water interfaces (a) a (100) surface, (b) a stepped $\mathrm{Pt}(221)$ surface and (c) a $147 \mathrm{Pt}$ atom nanoparticle surrounded by 428 water molecules. 


\section{Effect of OH Coverage}

The higher overpotentials associated with oxygen reduction over Pt are the result of the formation of hydroxyl surface intermediates which act to shutdown adsorption sites and impede the kinetics. While there has been a wealth of studies on the ORR pathways and kinetics, there has been little focus however on coverage effects. The results reported herein show that the higher $\mathrm{OH}^{*}$ coverages block available surface sites which impede the kinetics. In addition, however, the higher coverages can also act ot enhance the kinetics by forming hydrogen bonds that stabilize particular transition states. Surface $\mathrm{OH}$ groups can directionalize the bonding of surface intermediate and subsequently increase the binding energies of various molecules which will increase some of the intrinsic activation barriers while impeding others.

We have shown previously that ORR proceeds via the adsorption of molecular oxygen in a di- $\sigma$ mode on Pt followed by its protonation to form a surface hydro-peroxy $(\mathrm{OOH})$ intermediate or through the direct dissociation of $\mathrm{O}_{2}$ on the surface into chemisorbed oxygen atoms. The former is the more viable route under reaction conditions [25]. Herein we examine the influence of $\mathrm{OH}$ coverage on all of the possible steps proposed ORR mechanism. Our initial efforts have focused on the surface chemistry under ultrahigh vacuum conditions over Pt. This has recently been extended to the same reaction carried out in an aqueous medium.

\section{II.A. ORR at Zero Coverage in Vacuum}

We have examined the influence of $\mathrm{OH}$ coverage on the kinetics of the following reactions.

1) $\mathrm{O}_{2}+\mathrm{H} \rightarrow \mathrm{OOH}$

2) $\mathrm{O}_{2} \rightarrow \mathrm{O}+\mathrm{O}$

3) $\mathrm{OOH} \rightarrow \mathrm{O}+\mathrm{OH}$

4) $\mathrm{O}+\mathrm{H} \rightarrow \mathrm{OH}$

5) $\mathrm{OH}+\mathrm{H} \rightarrow \mathrm{H}_{2} \mathrm{O}$

The optimized reactants and products along with their transition states for each of these steps along with their corresponding activation barriers and overall reaction energies are given in Fig. 17 for low coverage $(0.11 \mathrm{ML})$ surface reactions. The results clearly reveal that $\mathrm{O}_{2}$ activation proceeds, even at low coverage and in the absence of water via the protonation (reduction) of $\mathrm{O}_{2}$ and the activation of the hydroperoxo intermediate rather than by direct $\mathrm{O}_{2}$ scission. The results also indicate that the protonation of a chemisorbed oxygen atom does not occur.

\section{II.B. Coverage Effects}

Reaction Energies for $\mathrm{O}-\mathrm{O}$ Bond Breaking Reactions

The reaction energies for all of the steps which involve the activation of the $\mathrm{O}-\mathrm{O}$ bond become less favorable with increasing the $\mathrm{OH}$ surface coverage. This is expected as the two products that form are destabilized by neighboring $\mathrm{OH}$ intermediates to a much greater extent than the reactant molecule is. The changes in the overall reaction energy with coverage for the splitting of the $\mathrm{O}_{2}$ bond in adsorbed $\mathrm{OOH}$ and $\mathrm{O}_{2}$ intermediates are shown in Fig. 18. The decrease in the exothermicity of the reaction becomes significantly greater as the $\mathrm{OH}$ coverage is increased above $0.5 \mathrm{ML}$. This is the result of significant repulsion due to metal atom sharing in the adlayer. The activation barriers are thus expected to increase in a similar way following the EvansPolanyi relationship. 


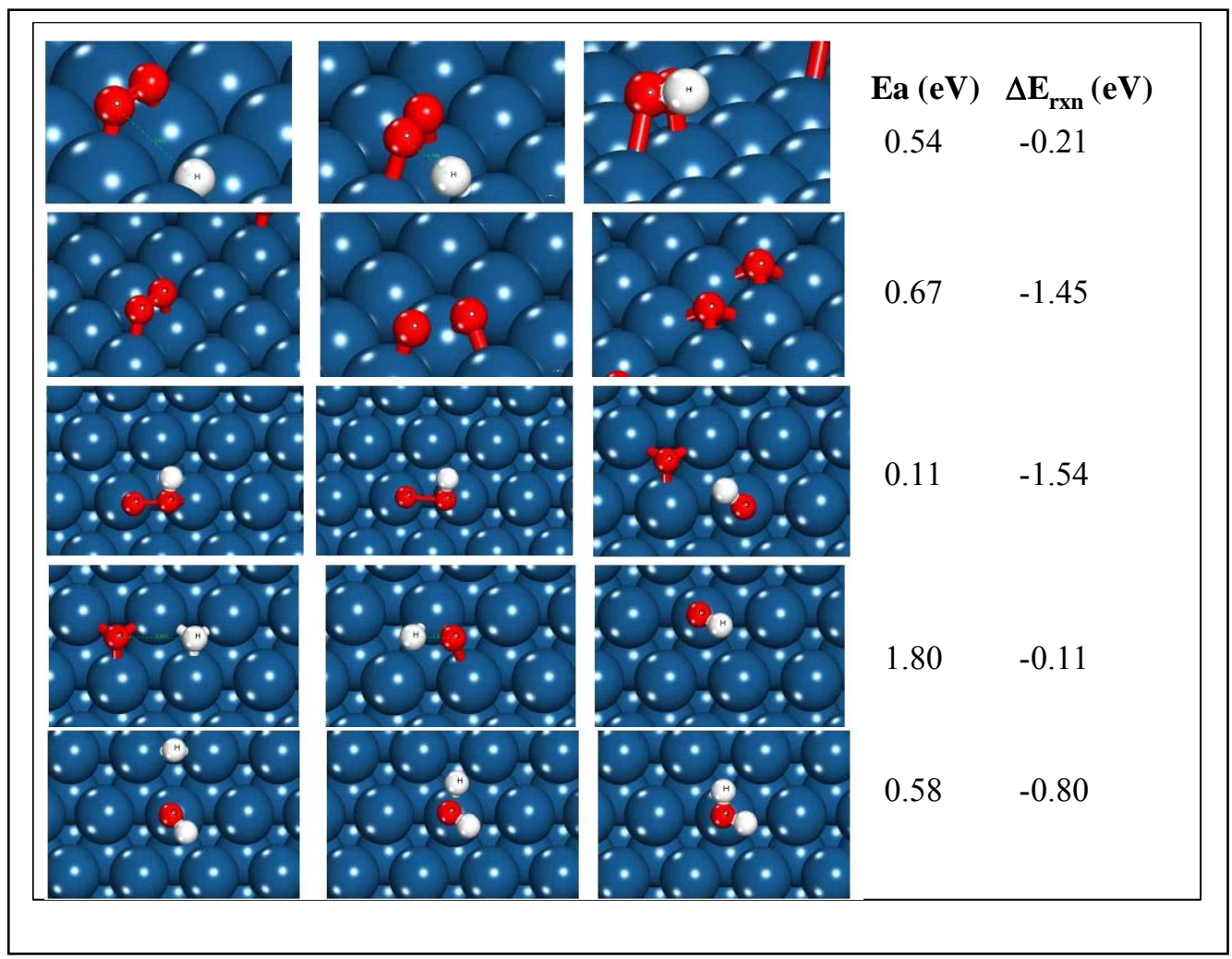

Fig. 17 DFT calculated reaction energies and activation barriers for the elementary steps in ORR at low coverage (1/9 ML).

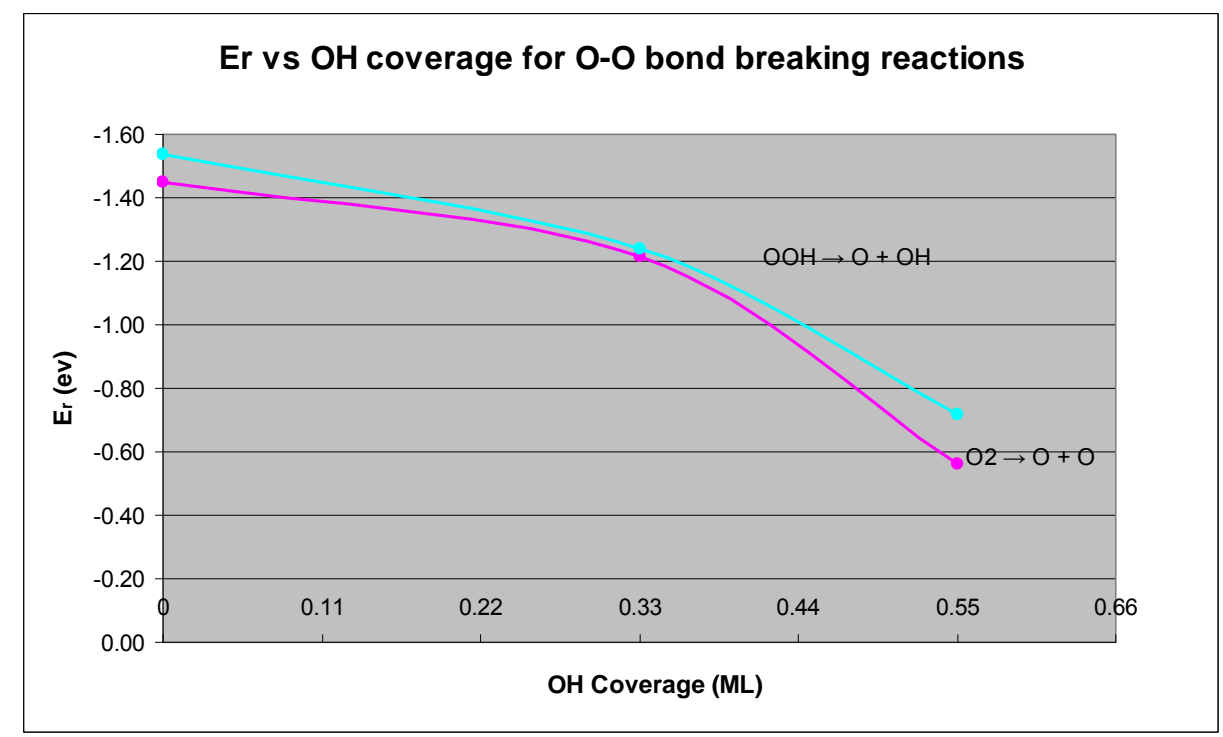

Fig 18. Variation of reaction energy with $\mathrm{OH}$ coverage for the O-O bond breaking reactions associated with ORR.

\section{Reaction Energies for $\mathrm{O}-\mathrm{H}$ Bond Forming Reactions}

The reaction energies for all of the $\mathrm{O}-\mathrm{H}$ bond forming steps become more exothermic as the coverage increases. As this is a bond-making reaction the energies are expected to become more favorable as we increase the surface coverage as result of the destabilization of the two reactant intermediates over the single product state. This is shown quite clearly in the Fig. 19 below for 
the reaction of $\mathrm{O}+\mathrm{H}, \mathrm{OH}+\mathrm{H}$ and $\mathrm{O}_{2}+\mathrm{H}$. In a similar manner, the activation barriers are expected to decrease with increasing $\mathrm{OH}$ coverage.

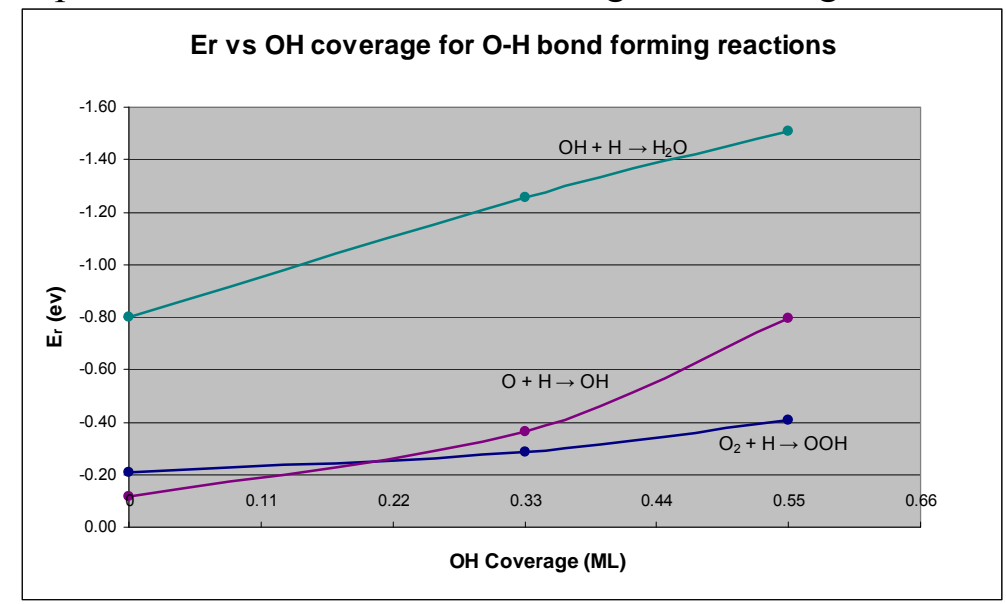

Fig 19. Variation of reaction energy with $\mathrm{OH}$ coverage for the $\mathrm{O}-\mathrm{H}$ bond forming reactions associated with ORR.

\section{Comparison of Activation Barriers for the Elementary Reactions Involved in ORR}

1) $\mathrm{O}_{2}+\mathrm{H} \rightarrow \mathrm{OOH}$

The barrier for the initial reduction of the adsorbed $\mathrm{O}_{2}$ decreases with the $\mathrm{OH}$ surface coverage as is shown in Fig. 20. This is consistent with the decrease in the binding energy for both $\mathrm{O}_{2}$ and $\mathrm{H}$ with coverage and an increase in the overall reaction endothermicity shown in Fig. 18.

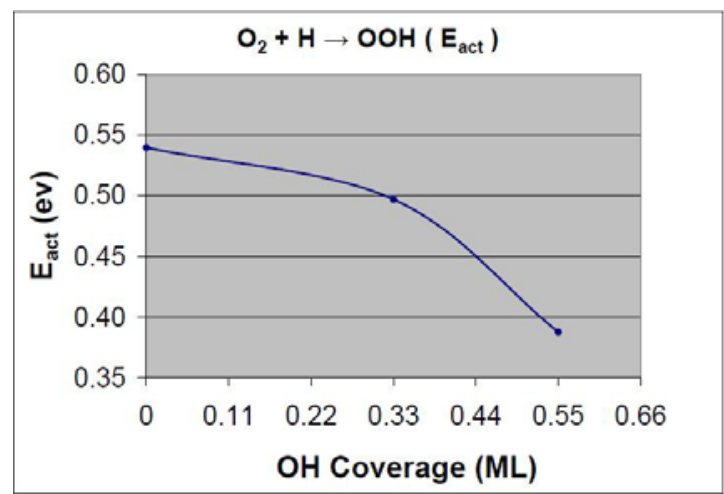

Fig 20 Changes in the activation barriers for the reaction a) $\mathrm{O}_{2}+\mathrm{H} \rightarrow \mathrm{OOH}$

2) $\mathrm{O}_{2} \rightarrow \mathrm{O}+\mathrm{O}$

The activation barrier for splitting of adsorbed oxygen demonstrates very unique changes with coverage. The barrier initially increases as the longer range electronic interactions act to weaken the binding energy of oxygen to the surface and make the reaction less favorable as is shown in Fig. 21a. Beyond 0.333 ML, we find that the activation barrier begins to decrease. This is due to the fact the two atomic oxygen intermediates that form in the transition state are stabilized via hydrogen bonding with the neighboring $\mathrm{OH}$ groups. These variations in the activation barrier can readily be explained by the changes that result in the binding energy of adsorbed $\mathrm{O}_{2}$ (Fig. $21 b)$. The stronger the oxygen molecule is bound to the surface the more difficult it is to dissociate it. 

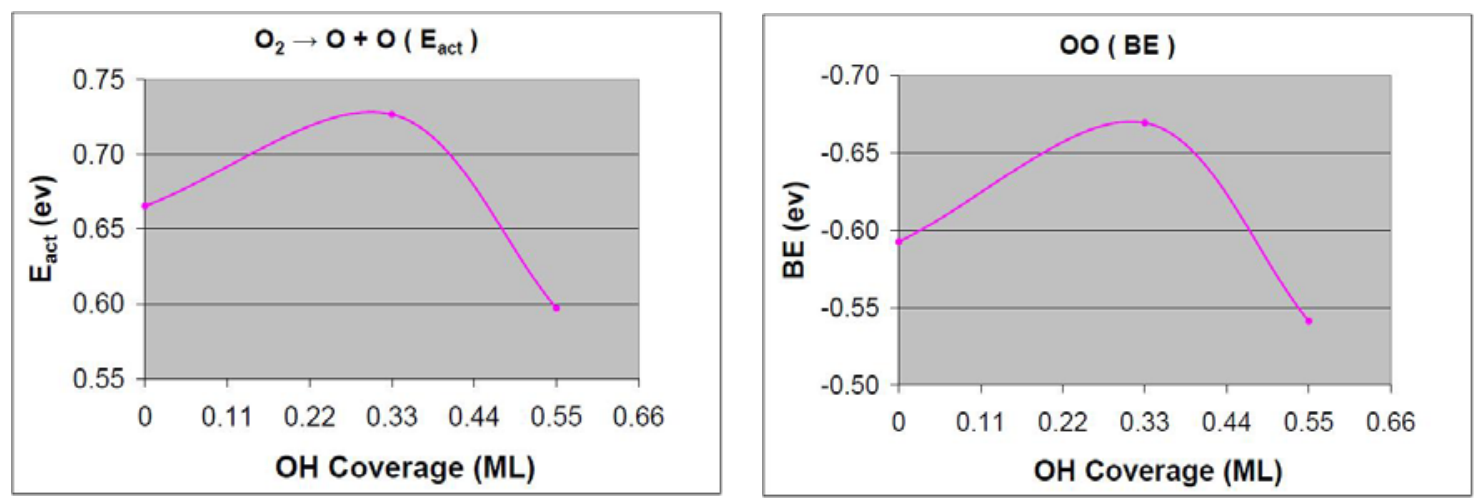

Fig 21: Variation in a) the activation barrier for $\mathrm{O} 2$ dissociation and b) the binding energy of the reactant molecule with coverage

3) $\mathrm{OOH} \rightarrow \mathrm{O}+\mathrm{OH}$

The trends for the activation of the $\mathrm{O}-\mathrm{O}$ bond from the adsorbed $\mathrm{OOH}$ intermediate show essentially the same trends as those found for the activation of $\mathrm{O}_{2}$. The barrier proceeds through a maximum at coverages of $0.33 \mathrm{ML}$ as might be expected. The results are presented here in Fig. 22a.
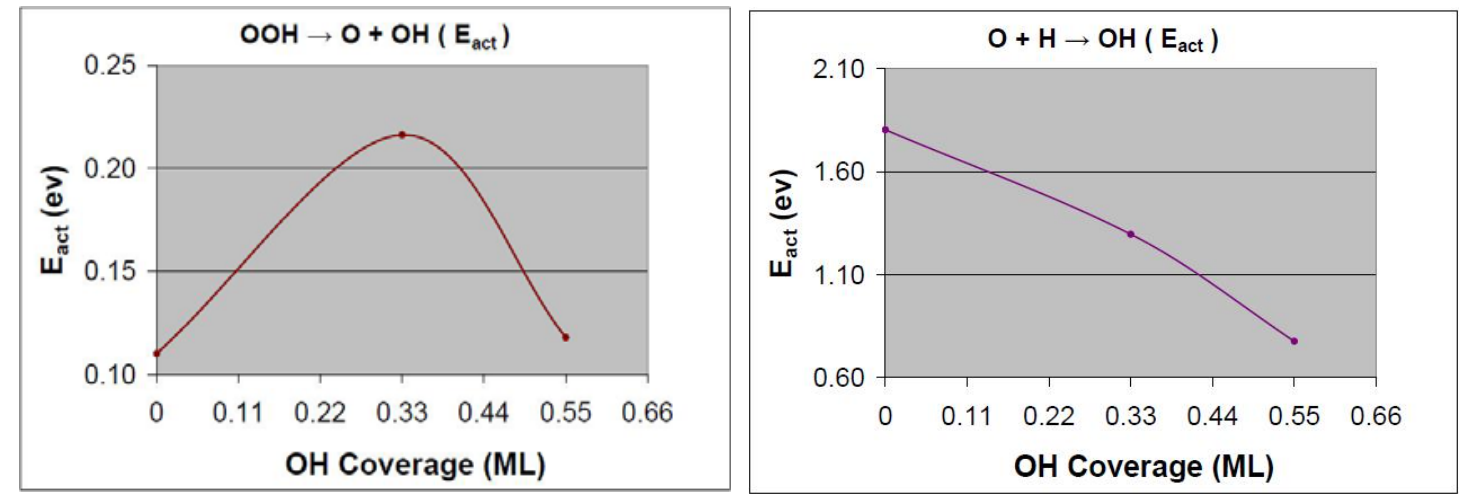

Fig 22: Changes in the activation barriers for the reaction of a) $\mathrm{OOH} \rightarrow \mathrm{O}+\mathrm{OH}$ and b) ) $\mathrm{O}+\mathrm{H} \rightarrow \mathrm{OH}$ with $\mathrm{OH}$ coverage

4) $\mathrm{O}+\mathrm{H} \rightarrow \mathrm{OH}$

While the activation barrier for the protonation of oxygen drops quite sharply as the coverage increases, it is still the step with the highest activation barrier. This is shown above in Fig. 13b and is what should be expected from the trends shown in Fig. 19 for the variation of the reaction energy with coverage as the increases in surface coverage result in weakening the interaction both $\mathrm{O}$ and $\mathrm{H}$ on the surface which enhance their reactivity.

5) $\mathrm{OH}+\mathrm{H} \rightarrow \mathrm{H}_{2} \mathrm{O}$

The activation barrier for the protonation of surface $\mathrm{OH}$ intermediates decrease with coverage up until $0.33 \mathrm{ML}$ of oxygen as is seen in Fig. 23. Beyond this point there is a stabilization of the $\mathrm{OH}^{*}$ and $\mathrm{H}^{*}$ surface intermediates at higher coverages as a result of hydrogen bonding between the surface intermediates and water. The results nicely follow the trends in the binding enegies of these intermediates. 


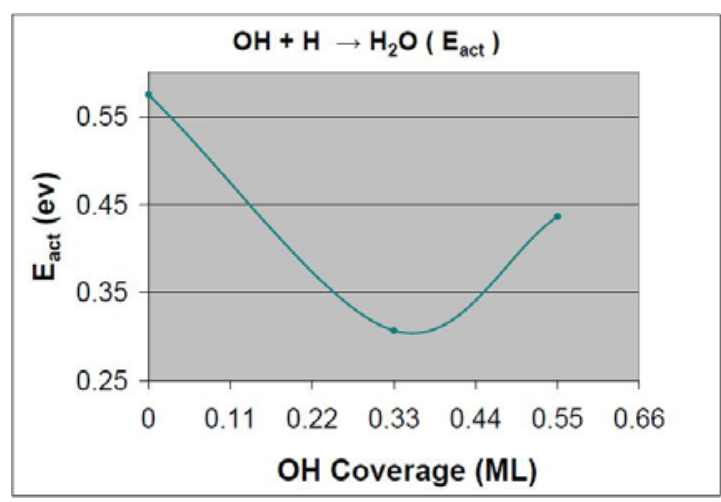

Fig 23: Variation of the activation barriers for the reaction $\mathrm{OH}+\mathrm{H} \rightarrow \mathrm{H}_{2} \mathrm{O}$ with $\mathrm{OH}$ coverage

\section{II.C. Summary}

- The protonation of $\mathrm{O}_{2}$ is preferred over the direct dissociation of $\mathrm{O}_{2}$ in ORR in initiating the reaction.

- Protonation reactions in general become more exothermic with increasing $\mathrm{OH}$ coverage.

- $\mathrm{O}-\mathrm{O}$ bond breaking reactions become less exothermic with increasing $\mathrm{OH}$ coverage.

- The changes in the activation barriers tend to follow the trends in the changes in the bond energies with coverage.

- The activation barrier for $\mathrm{O}+\mathrm{H} \rightarrow \mathrm{OH}$, has the highest value at zero coverage but falls sharply as coverage increases.

\section{II.D Studies for $\mathrm{OH}$ coverage with water present on the surface of $\mathbf{P t}$}

We have begun to extend these studies on the influence of $\mathrm{OH}$ surface coverage to simulations of the elementary ORR steps carried out in the presence of an aqueous solution at the metal interface. We have used 24 water molecules corresponding to a density of $0.91 \mathrm{~g} / \mathrm{cc}$ in the unit cell to simulate an aqueous environment on the surface of Pt.

We have examined the $0.55 \mathrm{ML} \mathrm{OH}$ surface coverage so as to probe what happens at the higher surface coverages. In these simulations 5 out of $6 \mathrm{H}_{2} \mathrm{O}$ molecules from the surface were converted to $\mathrm{OH}$ molecules and one was left as a $\mathrm{H}_{2} \mathrm{O}$ molecule. Simulated annealing simulations were carried out to establish the initial water layer structure which is shown below in Fig. 24. This structure was used in all subsequent calculations.

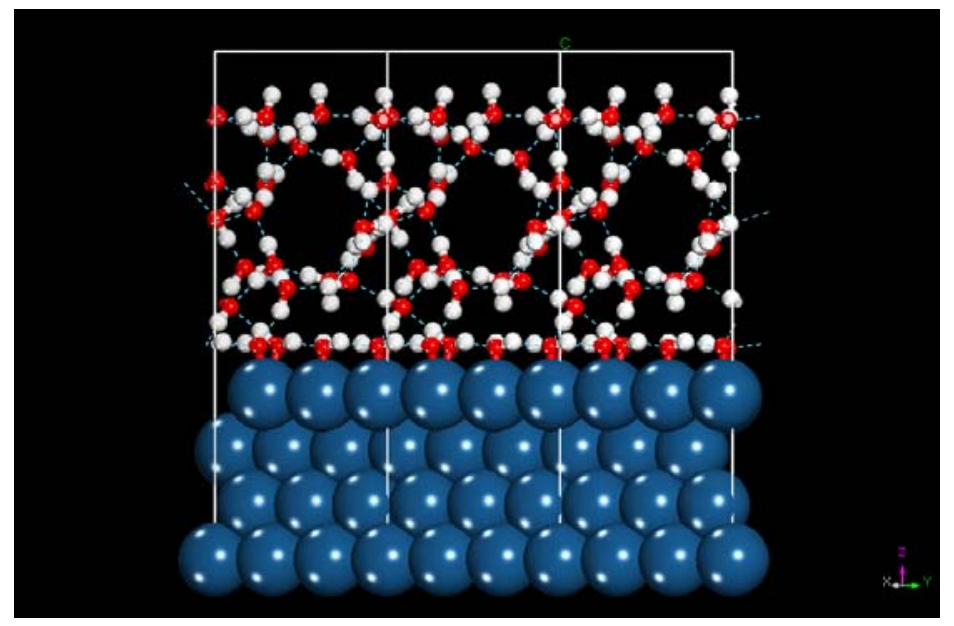


Fig 24. The aqueous/metal interface for water on $\mathrm{Pt}(111)$ with $0.55 \mathrm{ML} \mathrm{OH}$ coverage.

A comparison of the reaction energies as well as the activation barriers for the given elementary steps in the ORR mechanism at $0.55 \mathrm{ML}$ in both the vapor and aqueous medium are presented in Tables 3-5.

\begin{tabular}{|l|l|l|l|}
\hline & $\begin{array}{l}\Delta \mathbf{E}_{\text {rxn }} \mathbf{( e v )} \\
\text { Vacuum } \\
\mathbf{( 0 . 5 5} \mathbf{M L} \mathbf{~ O H})\end{array}$ & $\begin{array}{l}\Delta \mathbf{E}_{\text {rxn }} \\
\text { Solution } \\
\mathbf{( 0 . 5 5} \mathbf{M L} \mathbf{~ O H})\end{array}$ & Difference \\
\hline $\mathrm{O}_{2}+\mathrm{H} \rightarrow \mathrm{OOH}$ & -0.41 & -0.76 & -0.35 \\
\hline $\mathrm{O}_{2} \rightarrow \mathrm{O}+\mathrm{O}$ & -0.56 & -0.34 & 0.22 \\
\hline $\mathrm{OOH} \rightarrow \mathrm{O}+\mathrm{OH}$ & -0.72 & -0.33 & 0.39 \\
\hline $\mathrm{O}+\mathrm{H} \longrightarrow \mathrm{OH}$ & -0.8 & -0.3 & 0.5 \\
\hline $\mathrm{OH}+\mathrm{H} \rightarrow \mathrm{H}_{2} \mathrm{O}$ & -1.51 & -1.4 & 0.11 \\
\hline
\end{tabular}

Table 3: A comparison of the overall reaction energies for surface reactions in the vapor phase and in solution over $\operatorname{Pt}(111)$.

The results show that the overall reaction energies for all of the individual elementary steps for ORR become less exothermic with exception of the first protonation step $\left(\mathrm{O}_{2}+\mathrm{H} \rightarrow \mathrm{OOH}\right)$ when the reactions are carried out in an aqueous media. We expect that the individual activation energies (Ea) will also increase as would be predicted from Evans-Polanyi relationships.

The reactions nicely follow the trends set by the vapor phase results with the exception of the first reaction, where the Ea increases whereas we would expect it to decrease. This may be explained the differences in the binding energies of $\mathrm{O}_{2}$ on the surface in solution.

The binding energy of $\mathrm{O}_{2}$ does increase in the presence of solution on $\mathrm{Pt}$ (as does the activation energies for the reactions associated with $\mathrm{O}_{2}$ ).

\begin{tabular}{|l|l|l|l|}
\hline & $\begin{array}{l}\Delta \mathbf{E}_{\mathbf{a}} \mathbf{( e v )} \\
\text { Vacuum } \\
\mathbf{( 0 . 5 5} \mathbf{M L} \mathbf{~ O H})\end{array}$ & $\begin{array}{l}\text { Ea } \\
\text { Solution } \\
\mathbf{( 0 . 5 5} \mathbf{M L} \text { OH) }\end{array}$ & Difference \\
\hline $\mathrm{O}_{2}+\mathrm{H} \rightarrow \mathrm{OOH}$ & 0.39 & 0.48 & 0.09 \\
\hline $\mathrm{O}_{2} \rightarrow \mathrm{O}+\mathrm{O}$ & 0.6 & 0.78 & 0.18 \\
\hline $\mathrm{OOH} \rightarrow \mathrm{O}+\mathrm{OH}$ & 0.12 & 0.2 & 0.08 \\
\hline $\mathrm{O}+\mathrm{H} \rightarrow \mathrm{OH}$ & 0.78 & 1.79 & 1.01 \\
\hline $\mathrm{OH}+\mathrm{H} \rightarrow \mathrm{H}_{2} \mathrm{O}$ & 0.44 & 1.79 & 1.35 \\
\hline
\end{tabular}

Table 4: A comparison of the activation energies for surface reaction in the vapor phase and in solution over $\operatorname{Pt}(111)$.

\begin{tabular}{|l|l|lr|l|}
\hline & $\begin{array}{l}\text { Binding } \\
\text { Energy (ev) }\end{array}$ & $\begin{array}{l}\text { Binding } \\
\text { Energy }\end{array}$ & (ev) & Difference \\
\hline
\end{tabular}




\begin{tabular}{|l|l|l|l|}
\hline & $\begin{array}{l}\text { Vacuum } \\
\mathbf{( 0 . 5 5} \mathbf{~ M L ~ O H )}\end{array}$ & $\begin{array}{l}\text { Solution } \\
\mathbf{( 0 . 5 5} \text { ML OH) }\end{array}$ & \\
\hline Hydrogen Atom $(\mathrm{H})$ & -2.64 & -2.61 & 0.03 \\
\hline Oxygen Atom $(\mathrm{O})$ & -3.82 & -3.95 & -0.13 \\
\hline Hydroxyl $(\mathrm{OH})$ & -2.48 & -2.2 & 0.28 \\
\hline Water $\left(\mathrm{H}_{2} \mathrm{O}\right)$ & -0.84 & -0.78 & 0.06 \\
\hline Oxygen Molecule $(\mathrm{OO})$ & -0.54 & -0.63 & -0.09 \\
\hline Hydroperoxo Intermediate $(\mathrm{OOH})$ & -1.08 & -1.48 & -0.4 \\
\hline
\end{tabular}

Table 5: A comparison of the binding energies for intermediates bound to $\operatorname{Pt}(111)$ in vacuum and in solution. A higher negative value indicates that the specie is more strongly bound to the surface.

\section{Potential Effects on the Activation Energy}

The potential dependent reaction energies and activation barriers presented above in Section I all show parabolic behavior that can be fit to a simple quadratic equation to establish a course-grained model for the potential dependent for each of the activation barriers in the form of:

$$
r_{i}=v_{i} \exp \left(-\frac{E_{a}(U)}{R T}\right)
$$

The fit to the $\mathrm{O}_{2}$ reduction curve is shown in Figure 25 whereas the fit to the reduction of $\mathrm{OH}^{*}$ is shown in Fig. 26.

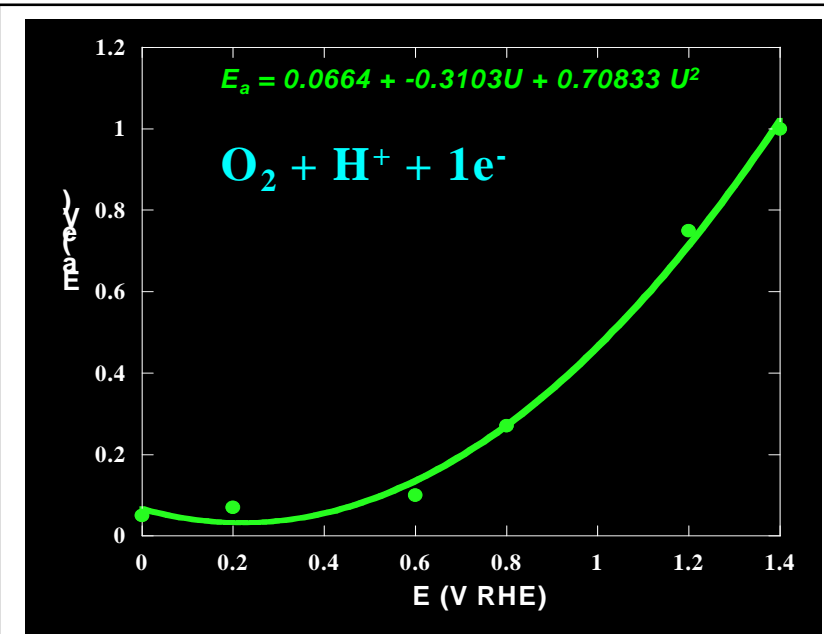

Figure 25. Quadratic fit of the DFT-calculated potential dependent reduction $\mathrm{O}_{2}$ to $\mathrm{OOH}$ for the development of coarse-grained model.

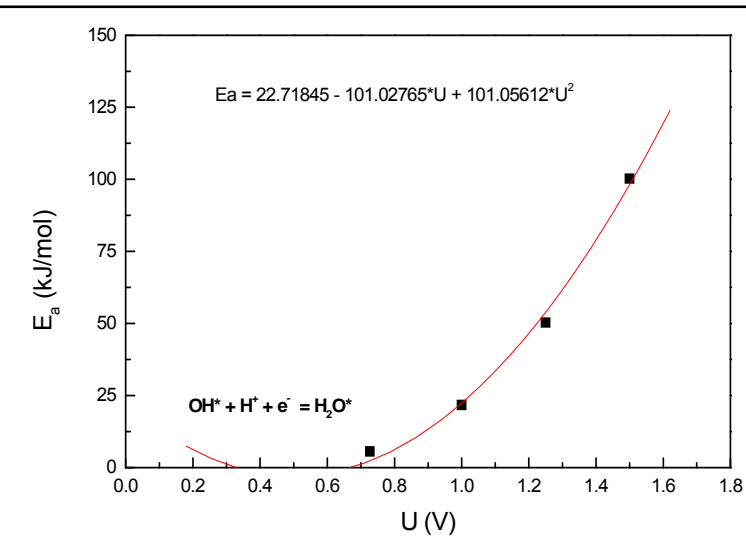

Figure 26. Quadratic fit of the DFT-calculated potential dependent reduction $\mathrm{OH}^{*}$ to $\mathrm{H}_{2} \mathrm{O} *$ for the development of coarse-grained model. 


\section{Kinetic Monte Carlo Simulation}

In order to follow the kinetics for the oxygen reduction reaction over Pt surfaces we used the potentialdependent and coverage dependent adsorption energies, reaction energies and activation barriers for the wide range of different elementary steps that result for all of the surface intermediates involve in the oxygen reduction reaction to establish an extensive ORR database on Pt surfaces and particles. The data was also used in the development of more course-grained models that can be used to fill in the data for specific conditions that were not explored. The models along with the kinetic data provide the input to 2D and 3D kinetic Monte Carlo simulation algorithms that were developed to simulate ORR under working conditions.

\section{A. 2D KMC Simulations of ORR}

As part of this DOE program we developed a first-principles base kinetic Monte Carlo simulation program that can simulate electrocatalysis over different single crystal surfaces $(111,100,110$ etc) for any metal or alloy provided one has carried out the appropriate DFT calculations to provide the input kinetic data. In addition, we extended the efforts to development of a 3D KMC algorithm to simulate the kinetics for ORR over 3D cubo-octahedral metal clusters. The simulation codes can be used to simulate a range of different experimental protocols and thus experiments. The simulations were used to ramp the potential and observe the kinetic behavior as we scan the potential of a wide range of values thus allowing us to simulate cyclic voltametric experiments. The results shown in Figure 27 show the CO stripping voltamograms over Pt and PtRu alloys.

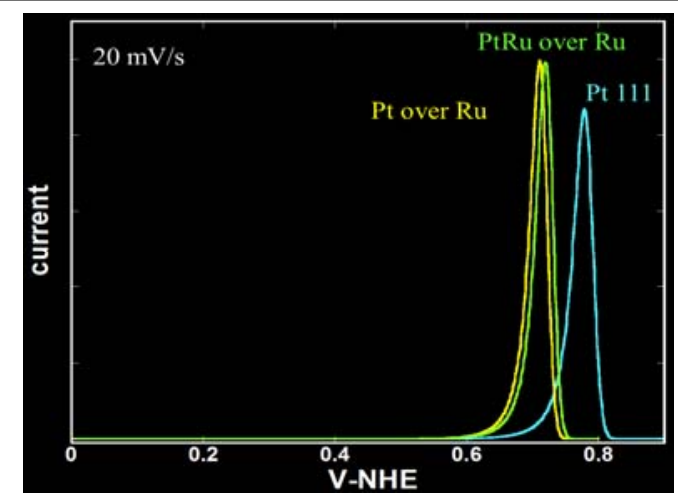

Figure 27. Simulated CO stripping

voltamogram over $\operatorname{Pt}(111)$, PtRu over $\operatorname{Pt}(111)$

and Pt over Ru(0001) surfaces. Scan rate of

$20 \mathrm{mV} / \mathrm{s}$.

Alternatively, we can hold the potential constant and examine the steady state catalytic behavior. As the surface structure is explicit, we can simply count the rate at which water molecules are formed as a function of time to determine the turnover frequency. These results can be subsequently used to determine the current density at a specific potential. Figures 28 and 29 shows a sequence of snapshots from a simulation of ORR on $\operatorname{Pt}(111)$. The structures shown in Figure 28 are those at early times within the simulations before the surfaces are covered or reach steady state. The structures seen in the snapshots shown in Figure 29 are those that form at steady state. One can see the much higher coverages of $\mathrm{OH}^{*}$ and other species that build up to provide a higher coverage adlayer. At $0.9 \mathrm{~V}$ the surface is covered in $\mathrm{OH}^{*}$ and other surface intermediates. One see the presence of $\mathrm{OH}^{*}, \mathrm{OOH}^{*}, \mathrm{O}^{*}$ and $\mathrm{H}_{2} \mathrm{O}^{*}$ all present under working conditions. 

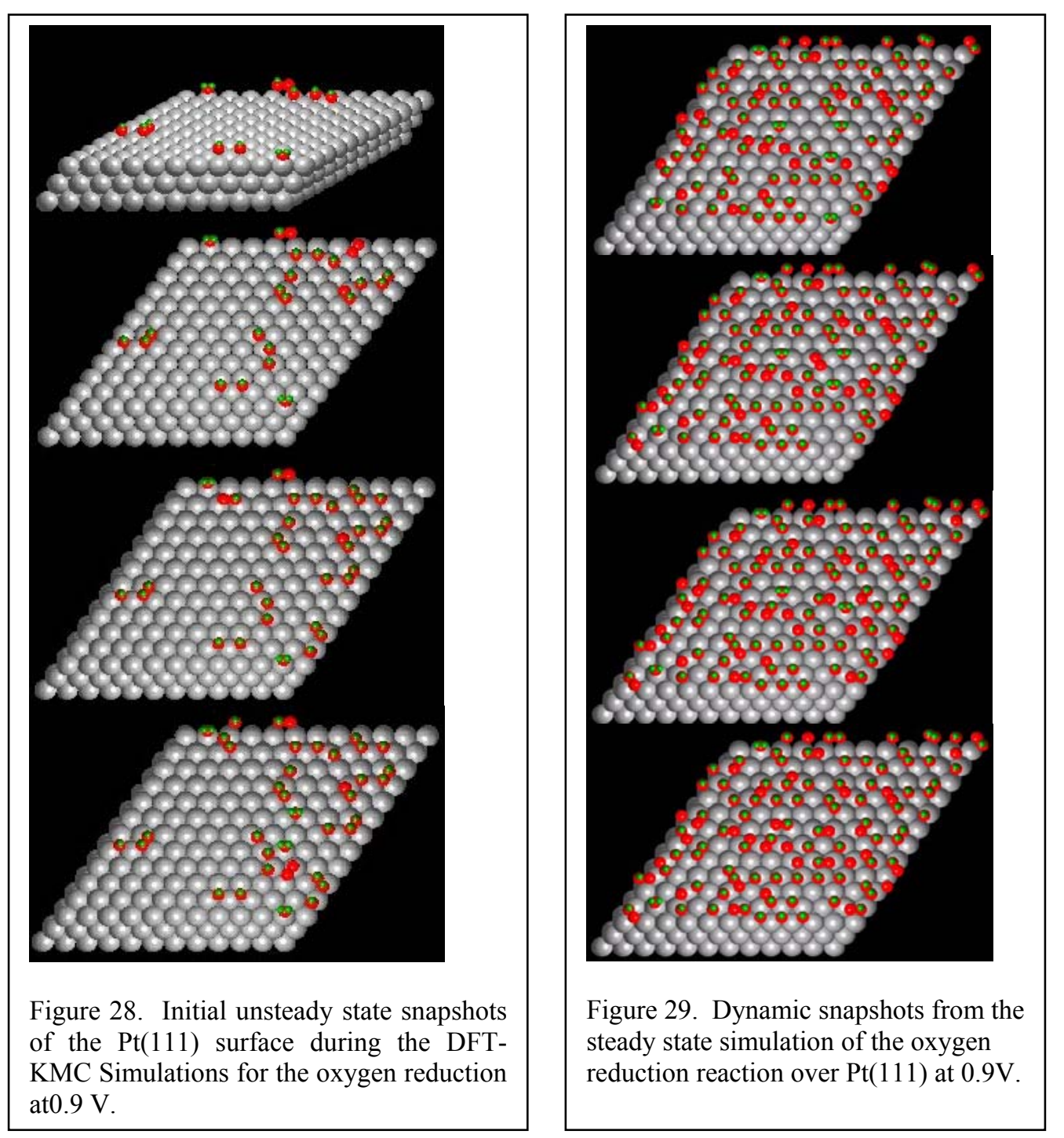

\section{3D - Kinetic Simulations of ORR}

In order simulate the kinetics over 3D nanoparticles, we first carried out an extensive set of DFT calculations on very large 147 atom metal clusters (presented early) submersed in over 400 water molecules as shown in Figure 30 in order to extend the DFT database for the (111) surface. These simulations were rather costly but allowed us to provide the energetics for individual steps in the ORR mechanism at different sites on the cluster including edge, corner, and 100 terrace sites (Figure 31). In addition, we carried out calculations over different stepped $\mathrm{Pt}$ surfaces including $\operatorname{Pt}(100), \operatorname{Pt}(221)$ and $\operatorname{Pt}(241)$. While we were not able to fully carry out the simulations to provide the full potential dependent behavior that we did for the 111 surface, we were able to systematically probe the barriers at a single potential at different sites. This was used to establish how changes in the metal atom coordination number influenced the elementary, $\mathrm{O}_{2}, \mathrm{HO}, \mathrm{O}$ reduction steps and the activation of $\mathrm{O}_{2}, \mathrm{OOH}$ and $\mathrm{HOOH}$. The results were used along with the results from the (111) surface to develop a more coarse-grained model to simulate the potential dependent behavior. The resulting kinetics provided the input needed to explicitly predict the intrinsic kinetics for all of the different sites on metal clusters within the 3D kinetic Monte Carlo simulations. 


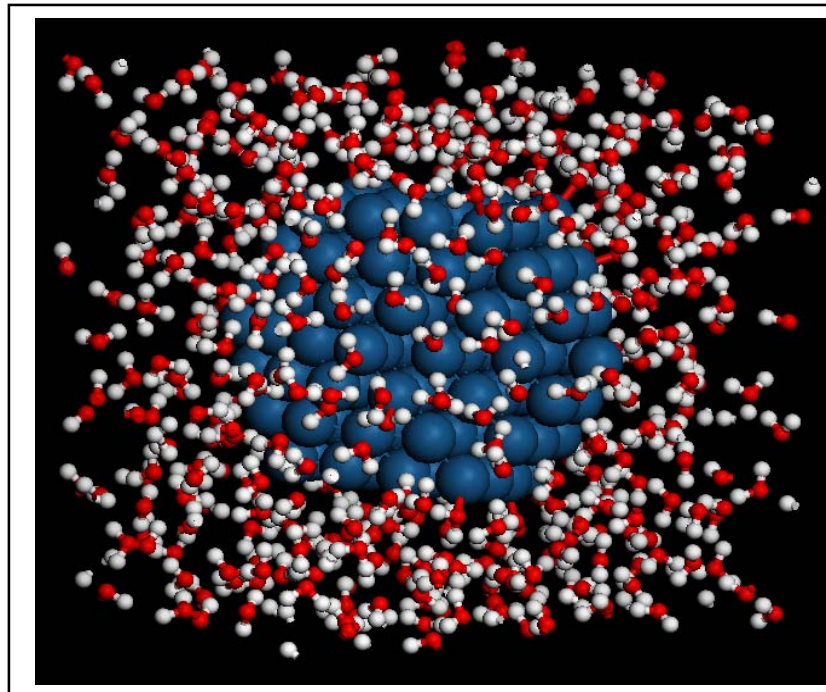

Figure 30. DFT potential dependent simulations for ORR on a Pt147 cluster in water.

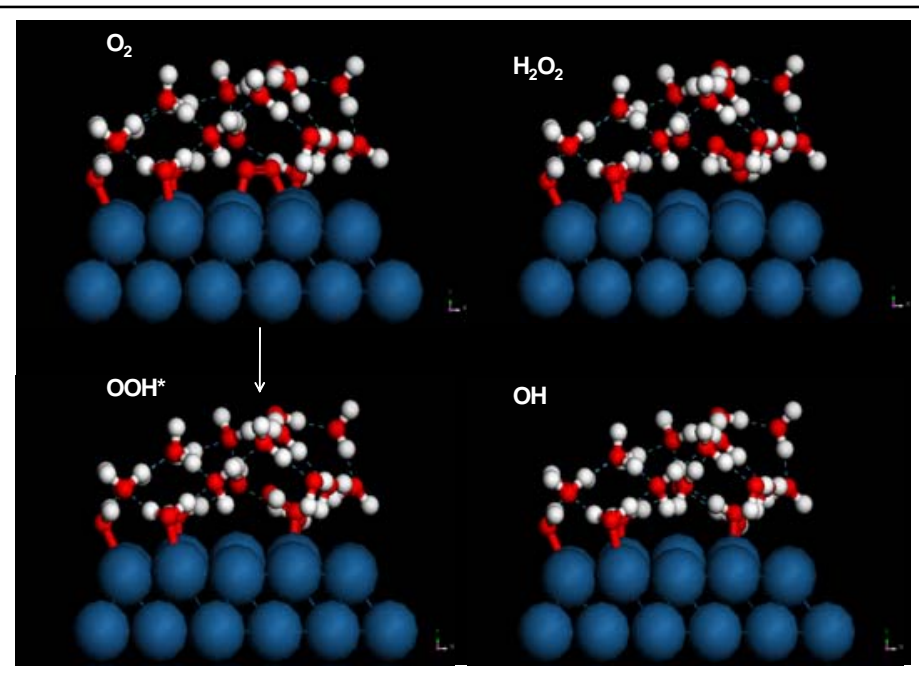

Figure 31. DFT-calculated structures and energies for $\mathrm{O}_{2}$, $\mathrm{OOH}^{*}, \mathrm{OH}^{*}$ and $\mathrm{H} 2 \mathrm{O} 2$ on $\mathrm{Pt} 147$ in aqueous water. The Full structures with water are shown in Figure 29.

The kinetics were used as input to the 3D KMC code. The 3D KMC simulations of ORR were carried out over $1.5 \mathrm{~nm}$ as well as $5 \mathrm{~nm}$ Pt clusters. The simulations monitored the elementary steps involved reduction of oxygen at a constant potential. The results examined herein were carried out at a potential of $0.9 \mathrm{~V}$ which is rather high. The simulations which follow the potential-dependent kinetics for all of the elementary steps reported in Figure. 13 were carried out at room temperature. The simulations were run as a function of time and carried out to $10,000 \mathrm{~s}$ in order to establish the steady state kinetics. A series of snapshots of the cluster surface depicted in Figure 32 taken after reaching steady state clearly show that the surface is highly covered in $\mathrm{OH}$ as well as other surface intermediates.

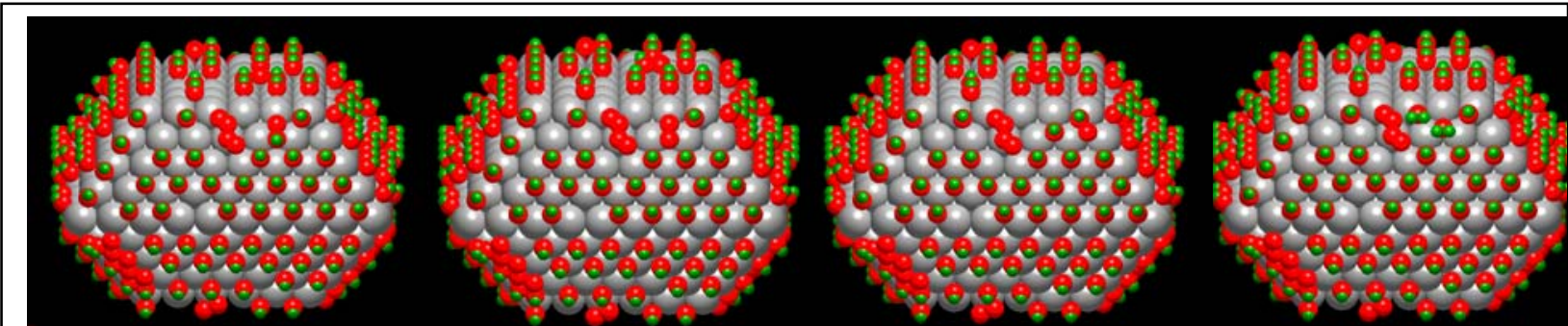

Figure 32. Dynamic snapshots from the steady-state simulation of ORR over $1.5 \mathrm{~nm}$ Pt clusters at $0.9 \mathrm{~V}$.

This is due to the fact that the simulations were carried out $0.9 \mathrm{~V}$ where water is readily activated but $\mathrm{OH}^{*}$ removal from the surface is difficult. The rates of $\mathrm{O}_{2}$ as well as $\mathrm{H}_{2} \mathrm{O}$ formation are shown in Figure 33. The results show that while water is clearly formed, its rate at $0.9 \mathrm{~V}$ is very low. If we divide the rate (molecules of $\mathrm{H}_{2} \mathrm{O}$ formed/second) by the number of sites on the surface of the cluster, we can calculate the turnover frequency. The calculated turn over frequency for simulations over the $1.5 \mathrm{~nm}$ Pt cluster at $0.9 \mathrm{~V}$ was $1.04 \times 10^{-4} \mathrm{~s}^{-1}$ which is very low. The low rate is due to the fact that $\mathrm{OH}$ dominates the surface and blocks sites. The surface coverages for all of the different intermediates were followed as a function of time and plotted in Figure 34. At $0.9 \mathrm{~V}$, the steady state $\mathrm{OH}$ coverage was calculated to be $0.7 \mathrm{ML}$ whereas the total coverage was found to be over $0.9 \mathrm{ML}$. As such, it is very difficult to establish high 
rates of the reaction at such a high potential as the surfaces are blocked. This is also consistent with known experimental results which show a limited electrocatalytic activity at potentials of $0.9 \mathrm{~V}$ and speculate that the surfaces are blocked by hydroxyl intermediates. [11, 13, 25]

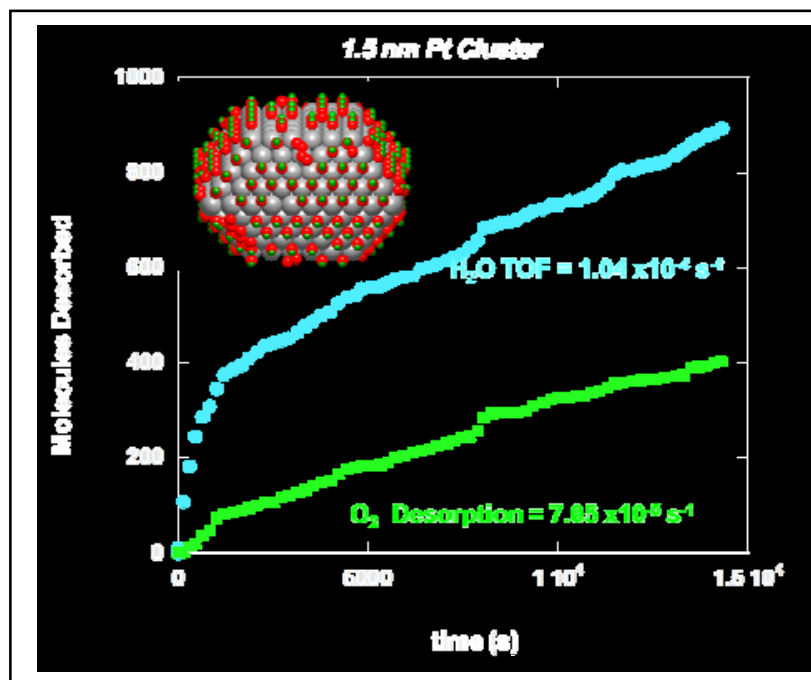

Figure 33. DFT-KMC simulation results for rates (turnover frequencies) for $\mathrm{H}_{2} \mathrm{O}$ formation and $\mathrm{O}_{2}$ desorption for ORR at $0.9 \mathrm{~V}$ over $1.4 \mathrm{~nm}$ Pt clusters.

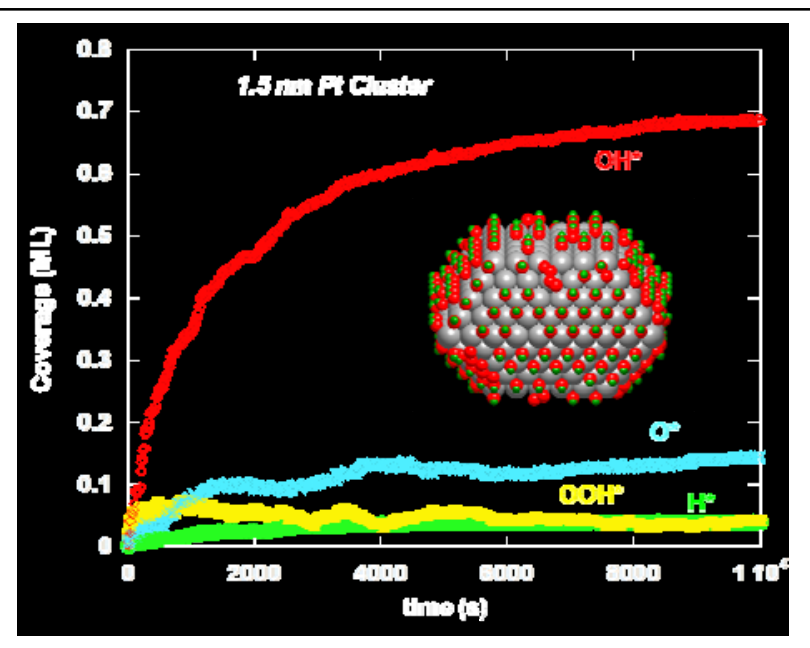

Figure 34. DFT-KMC simulation results for the coverages of $\mathrm{OH}^{*}, \mathrm{O}^{*}, \mathrm{OOH}^{*}$ and $\mathrm{H}^{*}$ for $\mathrm{ORR}$ at $0.9 \mathrm{~V}$ over $1.4 \mathrm{~nm}$ Pt clusters.

If we increase the particle size from $1.5 \mathrm{~nm}$ to $5 \mathrm{~nm}$, the steady-state turnover frequency increases by a factor of $1.5 \mathrm{x}$ as is shown in the results in the simulation results shown in Figure 35. The increase in the rate appears is due to the fact that the $\mathrm{OH}_{\mathrm{x}}$ intermediates on the terrace sites is more weakly bound to the surface and easier to reduce or desorb from the surface. The differences reported for the results on the 1.5 $\mathrm{nm}$ and $5 \mathrm{~nm}$ particles are predominantly due to the differences in the ratio of 111 terrace sites vs. edge and corner sites. Pioneering work by van Hardeveld and Hartog determined the fraction of terrace, edge and corner sites on model cubo-octahedral nanoparticles. Their results which are shown in Fig. 36 indicate that the fraction of terrace to edge and corner sites on the $1.5 \mathrm{~nm}$ particle is $0.67(0.39$ terrace/0.58 edge+corner) increases to 5.07 ( 0.71 terrace/ 0.14 edge and corner) in moving to $5 \mathrm{~nm}$ clusters. The $\mathrm{OH}$ binding energy on the terrace sites is significantly lower than that on the edge and corner sites. As a result the overall surface coverage on the $5 \mathrm{~nm}$ cluster is significantly less thus leading to the higher turnover frequencies.

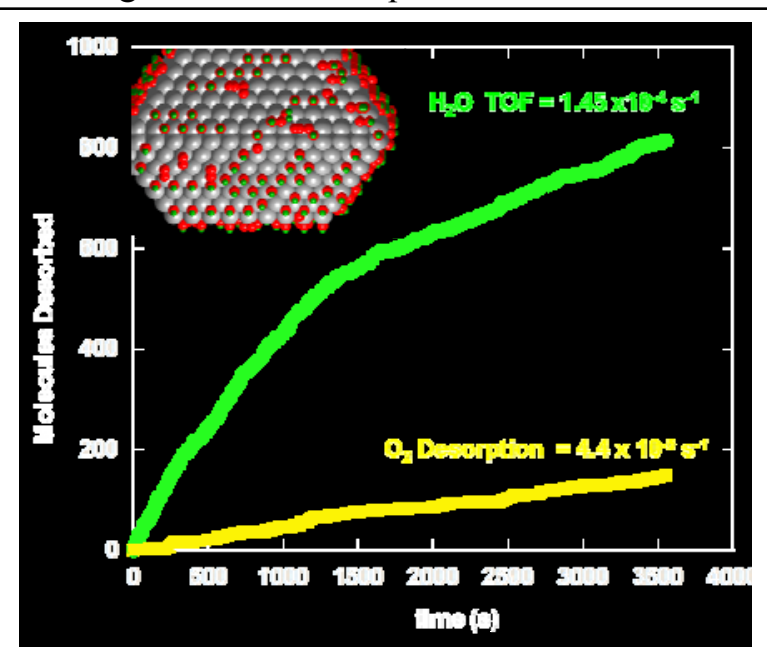

Figure 34. DFT-KMC simulation results for the turnover frequencies for $\mathrm{H}_{2} \mathrm{O}$ formation and $\mathrm{O} 2$ desorption for ORR at $0.9 \mathrm{~V}$ over $5 \mathrm{~nm}$ Pt clusters.

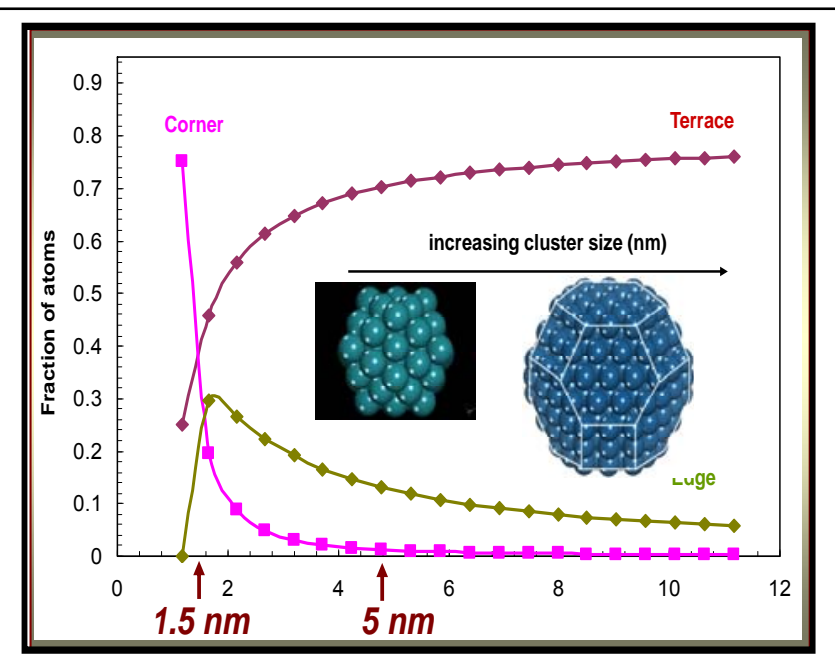

Figure 34. Size dependence of the fraction of corner, edge and terrace sites on cubo-ocohedral metal clusters. [1] 


\section{References}

1. Hartog, R.V.H.a.F., Surf. Sci., 1969. 5: p. 189-230.

2. Anderson, A.B., J. Roques, S. Mukerjee, V.S. Murthi, N.M. Markovic, and V. Stamenkovic, Activation Energies for Oxygen Reduction on Platinum Alloys:Theory and Experiment. J. Phys. Chem. B., 2005. 109: p. 1198-1203.

3. Janik, M.J., C.D. Taylor, and M. Neurock, First-Principles Analysis of the Initial Electroreduction Steps of Oxygen over Pt(111). Journal of the Electrochemical Society, 2009. 156(1): p. B126-B135.

4. $\quad$ Report, D.o.E., Basic Research Needs for the Hydrogen Economy. 2003. sss.sc.doe.gov/bes/hydrogen.pdf.

5. Toda, T., H. Igarashi, H. Uchida, and M. Watanabe, Enhancement of the electroreduction of oxygen on Pt alloys with Fe, Ni, and Co. Journal of the Electrochemical Society, 1999. 146(10): p. 3750-3756.

6. Stamenkovic, V., B.S. Mun, K.J.J. Mayrhofer, P.N. Ross, N.M. Markovic, J. Rossmeisl, J. Greeley, and J.K. Norskov, Changing the activity of electrocatalysts for oxygen reduction by tuning the surface electronic structure. Angewandte Chemie-International Edition, 2006. 45(18): p. 2897-2901.

7. Stamenkovic, V.R., B.S. Mun, K.J.J. Mayrhofer, P.N. Ross, and N.M. Markovic, Effect of Surface Composition on Electronic Structure, Stability, and Electrocatalytic Properties of Pt-Transition Metal Alloys: Pt-Skin versus Pt Skeleton Surfaces. J. Am. Chem. Soc., 2006. 128: p. 8813-8819.

8. Stamenkovic, V., B.N. Grgur, P.N. Ross, and N.M. Markovic, Oxygen Reduction Reaction on Pt and Pt-Bimetallic Electrodes Covered by CO: Mechanism of the Air Bleed Effect with Reformate. J. Electrochem. Soc., 2005. 152(2): p. A2770A282.

9. Markovic, N.M., H. Gasteiger, and P.N. Ross, J. Phys. Chem., 1996. 100: p. 6715.

10. Markovic, N., T.J. Schmidt, V. Stamenkovic, and P.N. Ross, Oxygen Reduction Reaction on Pt and Pt Bimetallic Surfaces: A Selective Review. 2001. 1(2): p. 105-116.

11. Mukerjee, S. and S. Srinivasan, Enhanced Electrocatalysis of Oxygen Reduction on Platinum Alloys in Proton-Exchange Membrane Fuel-Cells. Journal of Electroanalytical Chemistry, 1993. 357(1-2): p. 201-224.

12. Teliska, M., V.S. Murthi, S. Mukerjee, and D.E. Ramaker, Correlation of water activation, surface properties, and oxygen reduction reactivity of supported Pt-M/C bimetallic electrocatalysts using XAS. Journal of the Electrochemical Society, 2005. 152(11): p. A2159-A2169.

13. Mukerjee, S., S. Srinivasan, M.P. Soriaga, and J. McBreen, Role of Structural and Electronic-Properties of Pt and Pt Alloys on Electrocatalysis of Oxygen Reduction - an in-Situ Xanes and Exafs Investigation. Journal of the Electrochemical Society, 1995. 142(5): p. 1409-1422.

14. Thompsett, D., Pt Alloys as Oxygen Reduction Catalysts, in Handbook of Fuel Cells Fundamentals, Technology and Applications, A.L. W. Vielstich, and H.A. Gasteiger, Editor 2003, Wiley \& Sons: Chichester, UK. p. 467-480.

15. Watanabe, M., K. Tsurumi, T. Mizukami, T. Nakamura, and P. Stonehart, Activity and Stability of Ordered and Disordered Co-Pt Alloys for Phosphoric-Acid Fuel-Cells. Journal of the Electrochemical Society, 1994. 141(10): p. 2659-2668. 
16. Adzic, R.R., Recent Advances in the Kinetics of Oxygen Reduction, in Electrocatalysis, J. Lipkowski and P.N. Ross, Editors. 1998, Wiley-VCN. p. 197.

17. Filhol, J.S. and M. Neurock, "First-Principles Elucidation of the Electrochemical Activation of Water over Pd. Angew. Chemie Internation (Frontispiece), 2006. 45(3): p. 402-406.

18. Taylor, C.D., S.A. Wasileski, J. Fanjoy, J.S. Filhol, and M. Neurock, First Principles Reaction Modeling of the Electrochemical Interface: Consideration and Calculation of a Tunable Surface Potential from Atomic and Electronic Structure. Phys. Rev. B., 2006. 73(16): p. 165402.

19. Wang, J.X., F.A. Uribe, T.E. Springer, J.L. Zhang, and R.R. Adzic, Intrinsic kinetic equation for oxygen reduction reaction in acidic media: the double Tafel slope and fuel cell applications. Faraday Discuss., 2008. 140: p. 347-362.

20. Mun, B., M. Watanabe, M. Rossi, V. Stamenkovic, N.M. Markovic, and P.N. Ross, A Study of Electronic Structures of Pt3M Polaycrystalline Alloys with Valence Band Photoemission Spectroscopy. J. Chem. Phys., 2005. 123: p. 204717.

21. Nilekar, A.U., Y. Xu, J.L. Zhang, M.B. Vukmirovic, K. Sasaki, R.R. Adzic, and M. Mavrikakis, Bimetallic and ternary alloys for improved oxygen reduction catalysis. Topics in Catalysis, 2007. 46(3-4): p. 276-284.

22. Zhang, J., F.H.B. Lima, M.H. Shao, K. Sasaki, J.X. Wang, J. Hanson, and R.R. Adzic, Platinum monolayer on nonnoble metal-noble metal core-shell nanoparticle electrocatalysts for O-2 reduction. Journal of Physical Chemistry B, 2005. 109(48): p. 22701-22704.

23. Zhang, J.L., M.B. Vukmirovic, Y. Xu, M. Mavrikakis, and R.R. Adzic, Controlling the catalytic activity of platinum-monolayer electrocatalysts for oxygen reduction with different substrates. Angewandte Chemie-International Edition, 2005. 44(14): p. 21322135.

24. Sasaki, K., J.X. Wang, H. Naohara, N. Marinkovic, K. More, H. Inada, and R.R. Adzic, Recent advances in platinum monolayer electrocatalysts for oxygen reduction reaction: Scale-up synthesis, structure and activity of Pt shells on Pd cores. Electrochimica Acta, 2010. 55(8): p. 2645-2652.

25. Murthi, V., R.C. Urian, and S. Mukerjee, Oxygen Reduction Kinetics in Low and Medium Temperature Acid Environment: Correlation of Water Activation and Surface Properties in Supported Pt and Pt alloy Electrocatalysts. J. Phys. Chem. B, 2004. 108: p. 1101111023. 
